\title{
Cognitive consilience: primate non-primary neuroanatomical circuits underlying cognition
}

\author{
Soren Van Hout Solari ${ }^{1,2 *}$ and Rich Stoner ${ }^{3 *}$ \\ 1 Simigence Inc., Solana Beach, Cardiff, CA, USA \\ ${ }^{2}$ Department of Mechanical and Aerospace Engineering, University of California San Diego, La Jolla, CA, USA \\ ${ }^{3}$ Department of Neurosciences, Autism Center of Excellence, University of California San Diego, La Jolla, CA, USA
}

Edited by:

Julian Budd, University of Sussex, UK

Reviewed by:

Trygve B. Leergaard, University of

Oslo, Norway

Giorgio Innocenti, Karolinska

Institutet, Sweden

Hugo Merchant, Universidad Nacional

Autónoma de México, Mexico

\section{${ }^{*}$ Correspondence:}

Soren Van Hout Solari, Simigence Inc., 201 Lomas Santa Fe Suite 490, Solana Beach, CA 92075, USA.

e-mail: sorensolari@gmail.com

Rich Stoner, Department of

Neurosciences, Autism Center of

Excellence, University of California

San Diego, 8110 La Jolla Shores Road,

Suite 200, La Jolla, CA 92037, USA.

e-mail: rstoner@ucsd.edu
Interactions between the cerebral cortex, thalamus, and basal ganglia form the basis of cognitive information processing in the mammalian brain. Understanding the principles of neuroanatomical organization in these structures is critical to understanding the functions they perform and ultimately how the human brain works. We have manually distilled and synthesized hundreds of primate neuroanatomy facts into a single interactive visualization. The resulting picture represents the fundamental neuroanatomical blueprint upon which cognitive functions must be implemented. Within this framework we hypothesize and detail 7 functional circuits corresponding to psychological perspectives on the brain: consolidated long-term declarative memory, short-term declarative memory, working memory/information processing, behavioral memory selection, behavioral memory output, cognitive control, and cortical information flow regulation. Each circuit is described in terms of distinguishable neuronal groups including the cerebral isocortex (9 pyramidal neuronal groups), parahippocampal gyrus and hippocampus, thalamus (4 neuronal groups), basal ganglia (7 neuronal groups), metencephalon, basal forebrain, and other subcortical nuclei. We focus on neuroanatomy related to primate nonprimary cortical systems to elucidate the basis underlying the distinct homotypical cognitive architecture. To display the breadth of this review, we introduce a novel method of integrating and presenting data in multiple independent visualizations: an interactive website (http://www.frontiersin.org/files/cognitiveconsilience/index.html) and standalone iPhone and iPad applications. With these tools we present a unique, annotated view of neuroanatomical consilience (integration of knowledge).

Keywords: cerebral cortex, thalamus, basal ganglia, circuitry, consilience, isocortex, cognition

\section{INTRODUCTION}

At the turn of the twentieth century Cajal $(1899,2002)$ published what is considered now as the beginning of the modern anatomical understanding of the brain. Cajal's work, entirely dependent on the Golgi staining method, analyzed the neuroanatomical circuitry of complete brains in multiple species. His work stands out from 100 years of subsequent research as a single comprehensive examination across species and brain regions. Brodmann (1909) and von Economo (1929) respectively produced what are, surprisingly still today, the most comprehensive cytoarchitectonic maps of the human cerebral cortex. By the early 1970s, axonal tracing methods were introduced to study distant neuroanatomical projections (Graham and Karnovsky, 1966; Kristensson and Olsson, 1971). Tracing studies have continued to improve and produce detailed projection and connectivity data, but in so doing, fragment knowledge across species and brain regions (Zaborszky et al., 2006).

Forming an accurate mental view of brain circuitry is difficult, yet without one we cannot understand the function of the brain. Only with a comprehensive and cohesive picture can we make accurate inferences about the function of discrete neuroanatomical circuits. Each structure imposes dependencies and constraints on any theory that must be maintained for a working hypothesis of brain function. Several efforts are currently underway to reconcile the disparity between individual connectivity studies within a global scope. CoCoMac, a tool based on primate literature, represents the state of the art in mapping corticocortical interconnectivity between functional regions (Kotter, 2004). The Human Connectome Project (Marcus et al., 2011), along with other projects within the NIH Blueprint for Neuroscience Research, are using novel imaging methods to describe connectivity details for both primate and human brains (Stephan et al., 2000; Schmahmann et al., 2007; Hagmann et al., 2010). Unfortunately the resolution of external imaging methods is insufficient to elucidate neuroanatomical details underlying circuit organization.

This review is an attempt to form a comprehensive and cohesive understanding of the primate non-primary neuroanatomical circuitry through consilience (the integration of knowledge). Our first goal is to assemble a comprehensive neuroanatomical picture that is not inconsistent with known facts. We have produced an interactive visualization by synthesizing a vast number of fragmented studies into a single referenced framework that can be explored dynamically (Figure 1). We present this neuroanatomical picture as a detailed first-order approximation of 


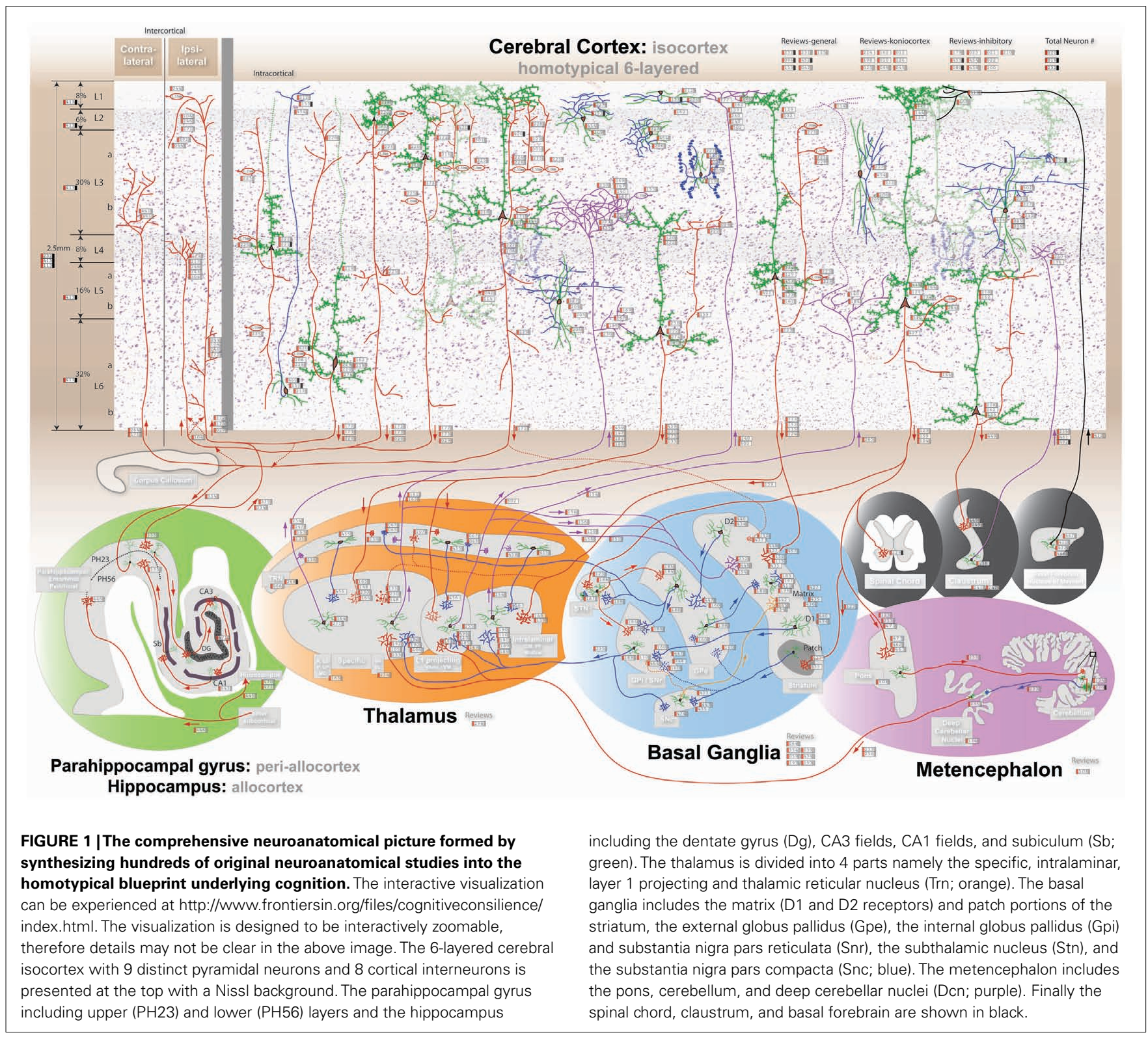

cognitive circuitry in the primate brain for use as a skeleton upon which to hang additional knowledge. The visualizations should be viewed as information static "interactive figures" associated with the review. The re-application of the technology and framework as an interactive tool with evolving information is a desirable future endeavor.

Our second goal is to synthesize the facts and patterns in the established neuroanatomical picture into a detailed functional framework consisting of seven discrete circuits that correspond to psychological perspectives on the brain. While neuroanatomy is necessary to understand the function of a brain, it is not sufficient. The vast amount of additional information from electrophysiology to psychology must be integrated and explained. For each circuit we provide a brief hypothesis of cognitive circuitry development and information flow at the neuron level. We understand that our novel functional perspective may generate healthy conversation and debate. The technology we provide offers an easily accessible medium in which to question, challenge, and verify the information presented.

Ultimately, cognitive consilience is an attempt to establish a unified framework within which the vast majority of knowledge on the primate brain can be placed.

\section{METHODS AND TECHNOLOGY: WEB, iPHONE, AND iPAD App}

Methodologically, the interactive Figure 1 was created by performing an extensive review of the non-primary primate literature, organizing the knowledge into a single framework, and selecting relevant reference data to include on the graphic. Non-primate data was utilized in occasions where primate data was insufficient or did not exist. In order to be placed on the graphic, reference data needed to contain sufficiently detailed location information 
by identifying an afferent/efferent cortical layer or subcortical nuclei. The graphic contains 410 referenced data visualization points from 186 unique references. By no means does this visualization include the complete body of neuroanatomical literature, but rather creates a comprehensive basis as a starting point for reader investigation. Data from many high quality citations could not be included as the data (raw or processed) was provided with insufficient spatial context. In general, we can only be as precise as the data we are reviewing. The graphic was hand drawn and attempts to recreate a reasonably accurate visual feel for structures, neurons, and their connectivity. Prominent axonal pathways were then identified as circuits, shown in Figure 4, based on known correlates with psychological and neuroscience data to provided a theoretical framework within which to understand neuroanatomy.

The review is accompanied by the release of an interactive web application $^{1}$ and a portable application for the Apple iPad and iPhone (search: cognitive consilience), illustrated in Figure 2. The interactive figure was built around a Google Maps-like interface to enable a reader to rapidly locate relevant citations. Each functional circuit discussed in the following sections can be toggled on and off to refine the presentation of important citations. Neurons and projections are directly referenced with appropriate links to PubMed and NeuroLex ${ }^{2}$. The web application provides additional search tools, including citation filters by publication date, species, author last name, and keywords.

The interactive medium provides a means for readers to rapidly evaluate hypotheses made in this review and to construct new ideas from the organized citations. The technology is presented as an information static "interactive figure" accompanying this review. Source code for the web application and raw citation data are available upon request and source code for the iphone/ipad app is available through collaboration. A future version that incorporates data mining and interactive citation addition is at the planning stage.

The inclusion of a spatially referenced interactive visualization accompanying a scientific review is novel and establishes a desirable new feature for future presentations of neuroanatomical work.

\section{PRIMATE NON-PRIMARY HOMOTYPICAL ARCHITECTURE}

Our near exclusive focus on primate non-primary data is unique. Neuroscience literature is biased toward studying primary sensory cortex in non-primates. This bias is introduced by the cost of primate research combined with the desire to correlate anatomical findings with electrophysiology stimulus response experiments.

As described in this review, the non-primary primate brain appears to have a consistent homotypical organization. The nonprimary isocortex contains important contrasting features not found in primary sensory koniocortex, yet general cortical organization, in nearly all neuroscience textbooks, is taught corresponding to koniocortical principles (Purves et al., 2004). Some examples of primate isocortical principles not found in koniocortex:

1. Specific thalamocortical projections target layer $3 \mathrm{~b}$ often avoiding layer 4,

\footnotetext{
${ }^{1}$ http://www.frontiersin.org/files/cognitiveconsilience/index.html

${ }^{2} \mathrm{http}: / /$ neurolex.org/
}

2. Lack of layer 4 spiny stellate cells,

3. Striatally projecting layer 5 neurons, and

4. Long corticocortical white matter projections including callosal projections.

If we are to understand the entire primate (human) brain, our understanding must be based on the correct neuroanatomy. In this paper, we focus on primate non-primary literature, and consciously avoid major discussion and citing of primary sensory literature. In so doing, we hope to establish a basis for the fundamental principles of brain circuit organization.

Brains follow general principles of development dictated by evolved gene expression patterns (Striedter, 2005; Watakabe et al., 2007); however, for any "rule" or general principle of organization, there can be found an exception to the rule. The described functional circuits are an attempt to elucidate the blueprint of the homotypical neuroanatomical architecture underlying cognition. When we refer to the blueprint of a homotypical architecture, we imply that the underlying neuronal organization and projection rules are the same across different regions of analogous nuclei. If a neuron type $\mathrm{X}$ sends its most dense projections to a target location $\mathrm{Z}$ and sends collateral projections to location $\mathrm{Y}$, we would consider $\mathrm{X} \rightarrow \mathrm{Z}$ the first-order neuroanatomical architecture. In order to create a compact yet comprehensive picture, we focus on the homotypical first-order architecture of the cerebral cortex, thalamus, basal ganglia, and their interconnections. This first-order architecture creates a factually consistent starting point upon which to build.

If we assume that neuroanatomical organization defines function, then a homotypical architecture supports the conjecture that different locations of the same neuronal group, although processing different information modalities, processes the information in the similar manner. Our viewpoint is that the cerebral cortex, thalamus, and basal ganglia only perform a limited few cognitive information processing functions. Within a homotypical architecture, each functional circuit determines how information is processed while the differences between the afferent input of two analogous pathways define what information is processed.

\section{NEUROANATOMICAL CIRCUITS}

Seven hypothesized functional circuits are presented. The seven circuits described are consolidated long-term declarative memory, short-term declarative memory, working memory/information processing, behavioral memory selection, behavioral memory output, cognitive control, and cortical information flow regulation. Each circuit is described in terms of readily distinguishable neuronal groups including the cerebral isocortex ( 9 pyramidal neuronal groups), parahippocampal gyrus and hippocampus, thalamus (4 neuronal groups), basal ganglia (7 neuronal groups), metencephalon, claustrum, basal forebrain, and spinal chord.

For clarity, each major neuronal group represented in the graphic is placed into only one primary circuit for discussion. However, in a functioning brain, circuits interact, and a single neuronal group participates in multiple circuits. The anatomical details of each circuit, shown in Figures 1 and 4, are meant to be explored dynamically through the associated technology. 


\section{A Web Application: Http://www.cognitiveconsilience.com}

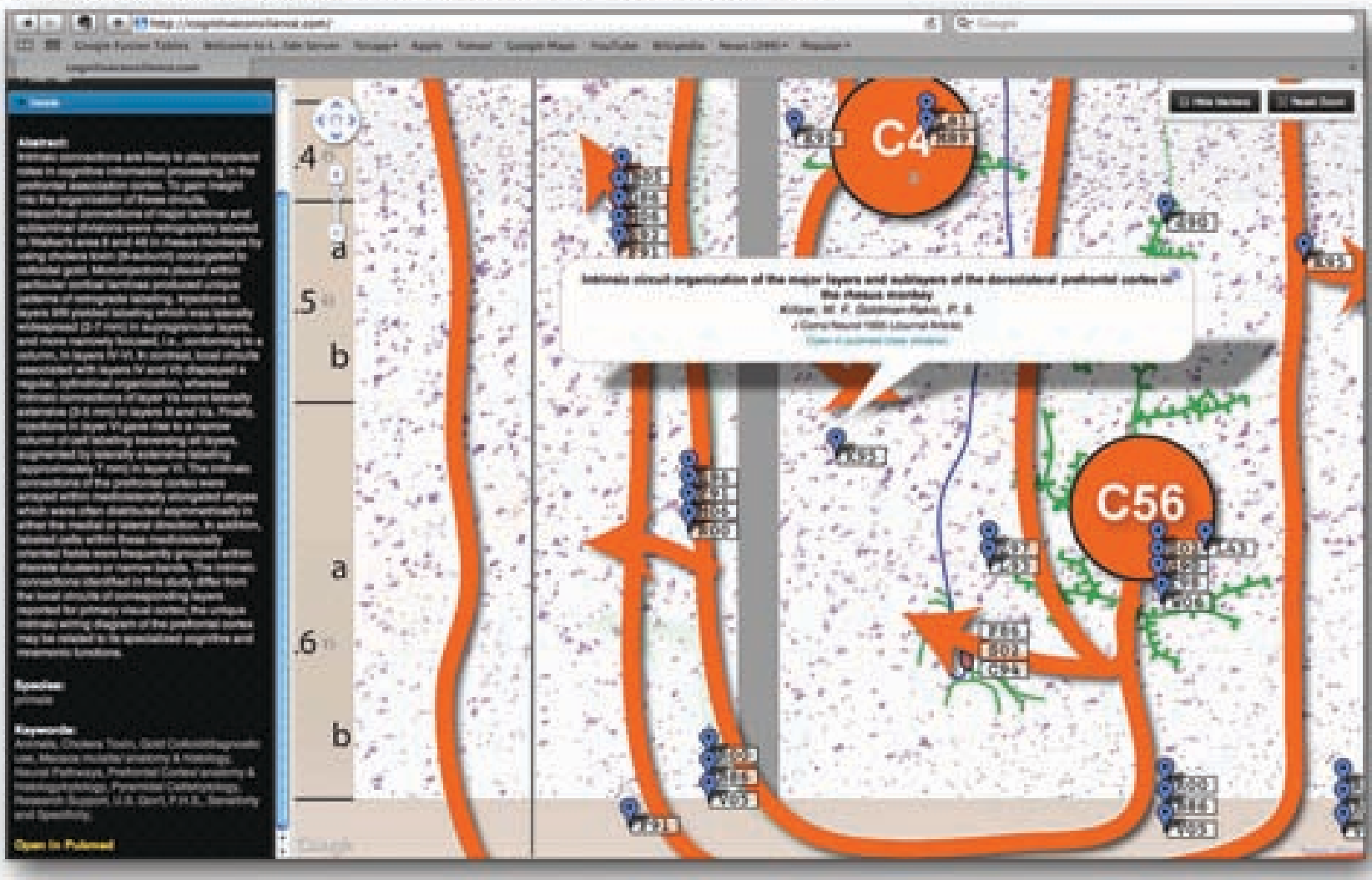

B iPad App

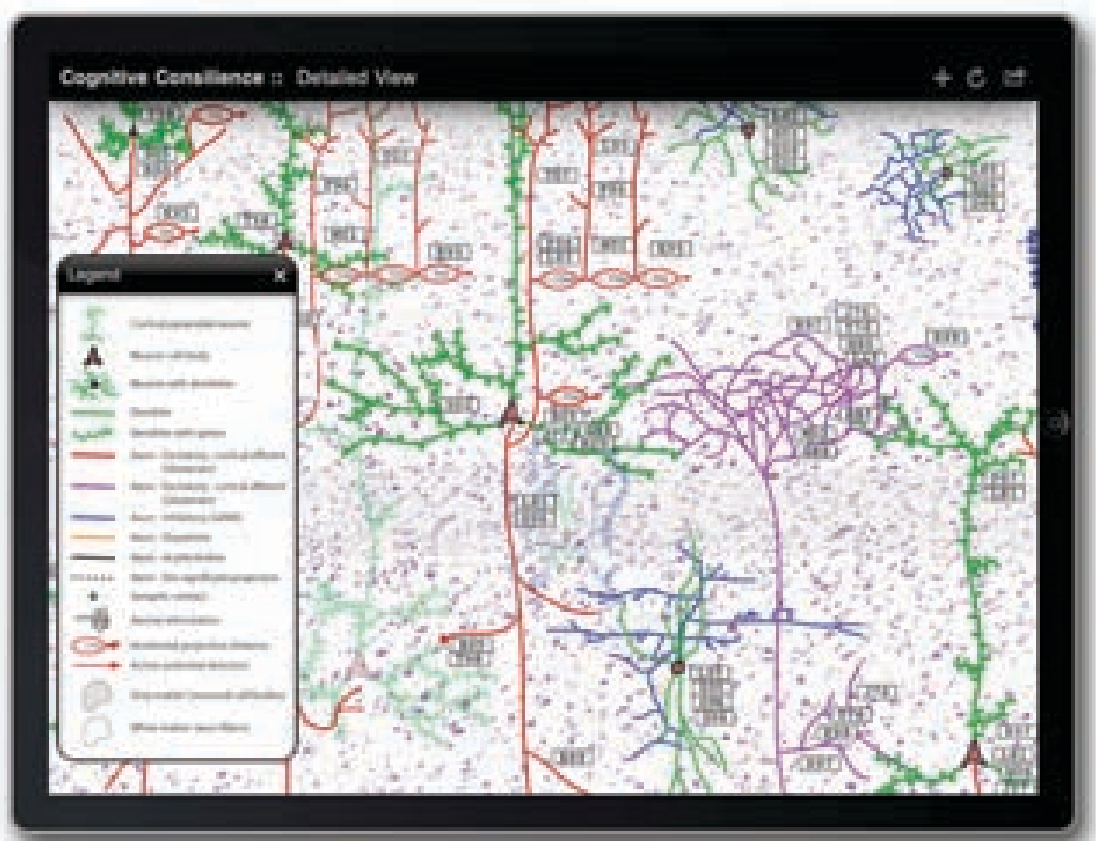

c iPhone App

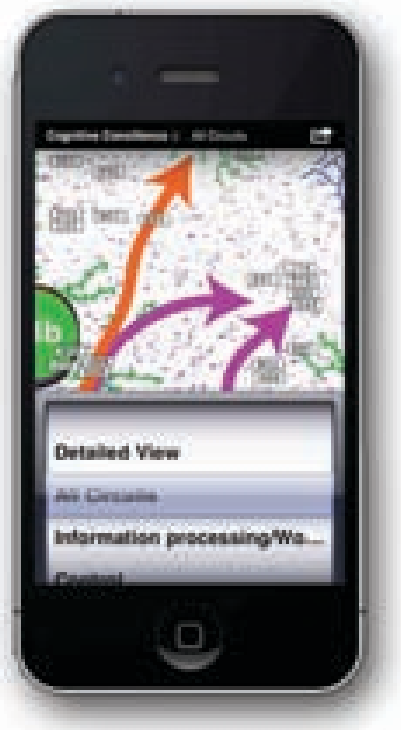

FIGURE 2 | Cognitive consilience visualization deployment across three technology platforms. The visualizations are identical and function similarly across platforms. (A) Interactive web application showing easy access to reference information throughout the visualization (http://www.frontiersin.org/files/ cognitiveconsilience/index.html). (B) Deployment as an iPad App. (C) Deployment as an iPhone App. 


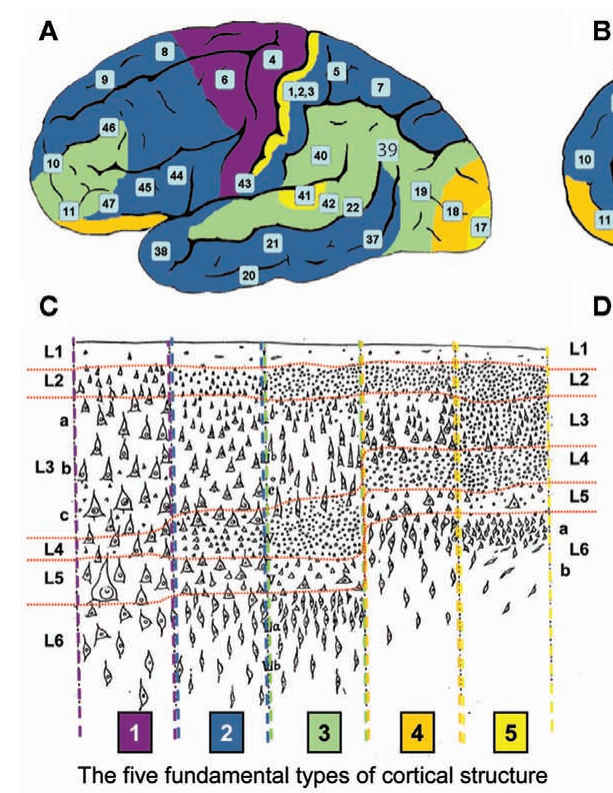

FIGURE 3 | Prediction of human laminar corticocortical projections. Synthesis of von Economo cortical laminar types and homotypical laminar corticocortical projections in the monkey. Lateral (A) and medial (B) view of human cortical regions colored to correspond to the five fundamental cortical types depicted in (C) with numbers corresponding to Brodmann's areas. (C) Von Economo's five fundamental human cortical lamination types (von Economo, 1929). $1=$ purple, 2 =dark blue, $3=$ green, $4=$ orange, $5=$ yellow. The laminar distribution in the human cerebral cortex can be identified along a smooth numerical gradient, where 5 corresponds to "input" granular koniocortex and 1 corresponds to "output" agranular cortex. Horizontal red lines highlight layer boundaries, with average human cortical thickness $=2.5 \mathrm{~mm}$. (D) Rough

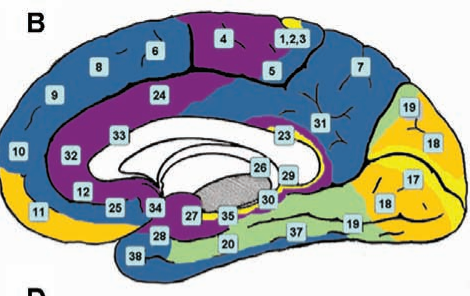

D

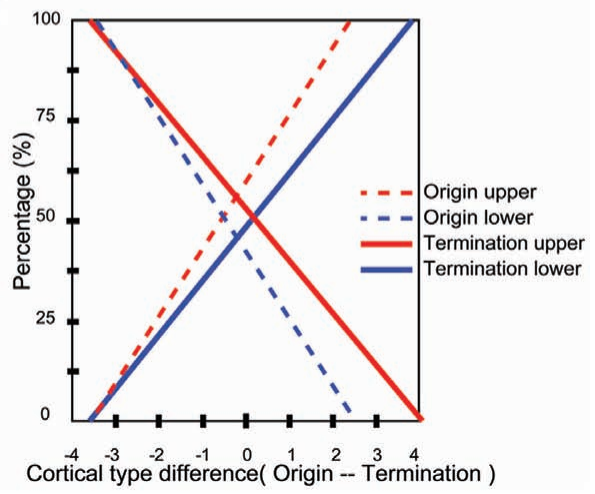

prediction of human laminar corticocortical (origin/termination) projection percentages predicted by numerical difference of cortical types in (C). Dotted red $=\%$ neurons originating in upper layers 2, 3. Dotted blue $=\%$ neurons originating in lower layers 5,6 , and lesser 4 . Solid red $=\%$ synaptic terminations in layers 1,2 , and lesser 3 . Solid blue $=\%$ synaptic terminations in mid/lower layers 4, 5, and lesser 6. In general,

"feedforward" = (dotted red/solid blue), "feedback" = (solid red/dotted blue). Example: A type 2 (blue origin) projecting to a type 4 (orange target) would have a difference of -2 (feedback), and predict roughly $25 \%$ of the projections from type 2 would originate from neurons in upper layers 2, 3, and roughly $20 \%$ of synaptic terminations in the type 3 cortical area would terminate in middle/lower layers.
The organization of the review follows a pattern to enable the reader to more clearly distinguish between neuroanatomical fact and the authors synthesized viewpoint. A subsection titled "perspective" concludes each circuit description and presents hypotheses and a more speculative synthesized viewpoint. All other sections attempt to conform to the unbiased presentation of important published information. We also include a concise summarized author's viewpoint on the function of each neuronal group following their neuroanatomical description indicated with "Viewpoint": Historical notes, indicated as such, are interjected to explain the current state of thinking and reinvigorate important concepts that seem faded in the literature.

\subsection{CONSOLIDATED LONG-TERM DECLARATIVE MEMORY: CORTICOCORTICAL CIRCUIT}

The identification of declarative memory is adopted from Squire as referring to "the capacity for conscious recollection about facts and events" (Squire, 2004). We define long-term memory as that which is stored semi-permanently in the isocortex. Lesions of the isocortex or of white matter fiber tracts produce a wide variety of stereotypical cognitive deficits (Geschwind, 1965b; Penfield and Rasmussen, 1968). Two distinct long-term memory deficits arise when comparing cortical gray matter lesions to corticocortical white matter lesions, although human lesions are rarely isolated (Geschwind, 1965a; Schmahmann et al., 2008). Localized gray matter lesions result in a reduced capacity to recall and process domain specific information, often manifesting as a form of agnosia (i.e., loss of the ability to recognize). For example, the inability of humans to recognize faces with lesions to the fusiform face area or recognize motion with lesions to cortical area MT. White matter lesions result in subtly different deficits representative of a disconnection of information shared between separate cortical areas. For example, lesions to the arcuate fasciculus disconnect Wernicke's area (speech comprehension) from Broca's area (speech production) and result in deficits in speech repetition (Damasio and Damasio, 1980). In essence, although speech comprehension and production both independently remain intact, the associations between them have been severed. These two distinct forms of long-term memory exist within the interconnectivity of the cerebral cortex.

\subsubsection{Cerebral cortex}

The human cerebral cortex is a $2.5-\mathrm{mm}$ thick sheet of tissue approximately $2400 \mathrm{~cm}^{2}$ (four $8.5 \times 11$ pieces of paper) in size folded up around the entire brain (Toro et al., 2008). The cerebral cortex consists of a homotypical six layer pattern of neuron density distribution (von Economo, 1929; Lorente de No, 1943). The cerebral cortex develops inside out, with neurons in the innermost 


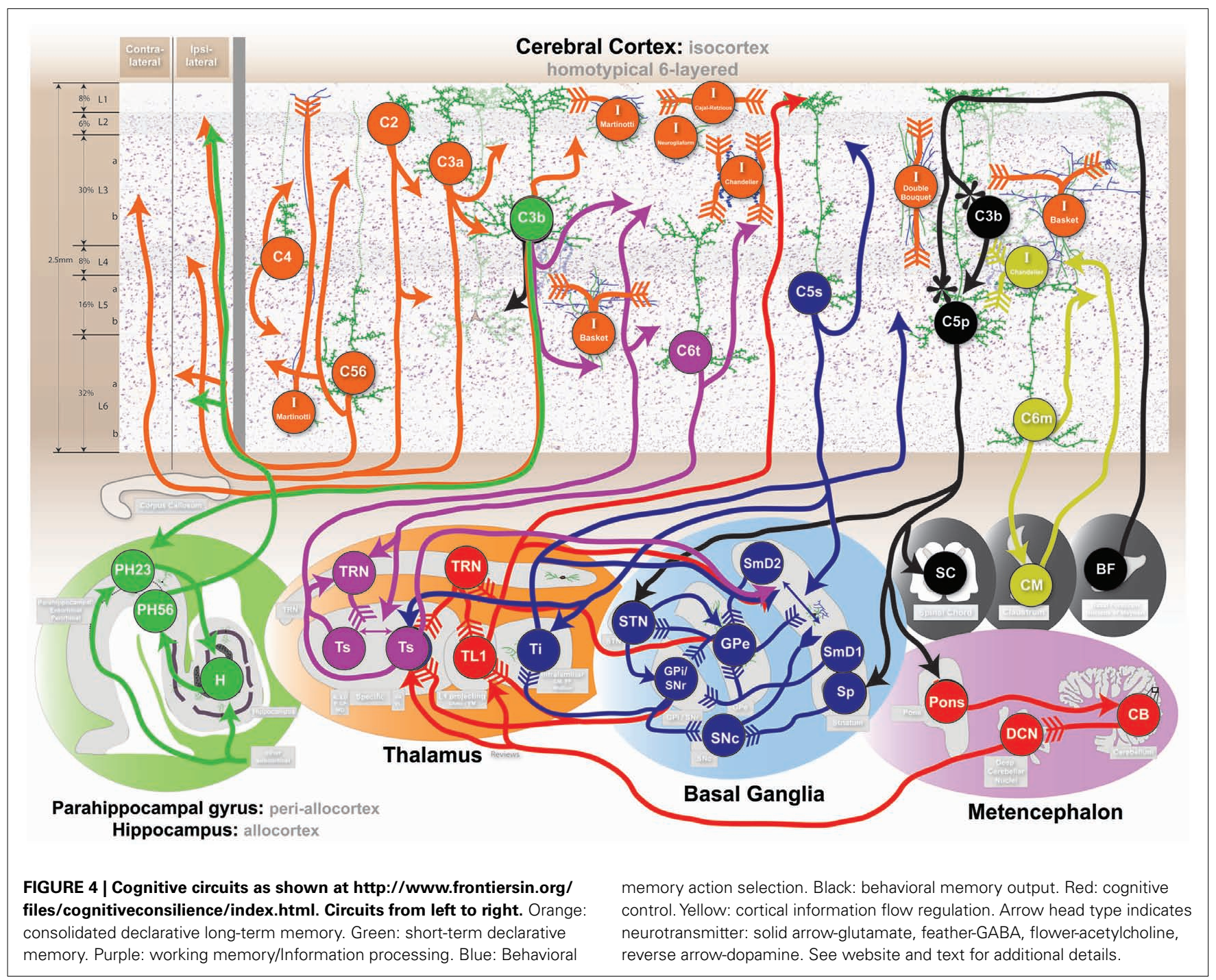

layer (L6) migrating into place first and neurons in successive outer layers migrating into place later (Rakic, 1995). Cortical laminar differentiation lies along a very clear spectrum with input sensory cortex being the most laminated/granular and output motor cortex being the least laminated/granular (von Economo, 1929; see Figure 3C). The lamination gradient represents a major clue in functional organization. The cerebral cortex can be grouped into the isocortex (neocortex), allocortex (paleocortex), periallocortex, and koniocortex (primary vision, auditory, somatosensory, and granulous retrosplenial cortex) based on laminar differentiation and developmental origin. The koniocortices are based on the same underlying anatomical principles of six layers and have evolved additional structure for their more specific sensory roles (Northcutt and Kaas, 1995). The patterns of laminar differentiation have been used to parse the entire cerebral cortex into distinct areas often called Brodmann's areas (Brodmann, 1909; Triarhou, 2007). A large amount of experimental evidence on the cerebral cortex, from lesion studies to electrophysiology to FMRI, point to localized cortical information processing modules on the order of a few $\mathrm{mm}^{2}$ (Szentagothai, 1975; Catani and ffytche, 2005). Each area appears to process a distinct type of information reflecting the external and internal perceptions/behaviors of the individual, such as visual objects, language, executive plans, or movements (Penfield and Rasmussen, 1968; Goldman-Rakic, 1996; Grafton et al., 1996; Tanaka, 2003). The what of cortical information processing is thus highly localized and modular. The neuroanatomical organization underlying these what regions follows a very homotypical blueprint, which drives a functional perspective that how information is processed throughout the cerebral cortex is the same.

\subsubsection{Intracortical circuit}

Intracortical projections are horizontal corticocortical projections traveling within the gray matter of the cerebral cortex (Kritzer and Goldman-Rakic, 1995). Although all pyramidal neurons have connections within the cerebral cortex, the prominent source of distant intracortical projections arise mainly from pyramidal neurons within layers 2 and 3 , and a sub-set of neurons in layers 5 and 6 . The intracortical terminations of $\mathrm{C} 3 \mathrm{a}$ and $\mathrm{C} 3 \mathrm{~b}$ pyramidal neurons are not distributed uniformly, but form patchy or stripe-like patterns of termination which comprise areas up to $20 \mathrm{~mm}^{2}$ in the monkey 
(de Lima et al., 1990; Levitt et al., 1993; Fujita and Fujita, 1996; Pucak et al., 1996). Neurons in each layer appear to project horizontally, then the stripe-like terminations (spaced a few $100 \mu \mathrm{m}$ apart) arise out of vertical collaterals. The laminar specificity and development of these corticocortical striped projections is largely activity dependent (Price et al., 2006). In the monkey, 50\% of pyramidal neuron synaptic contacts, within its local stripe (roughly its dendritic tree size), are onto GABAergic inhibitory neurons, while more than $90 \%$ of synaptic contacts outside a pyramidal neurons local stripe are onto other pyramidal neurons (Melchitzky et al., 2001). The intracortical organization is suggestive that a functional module $\left(\sim 10 \mathrm{~s} \mathrm{~mm}^{2}\right)$ in the isocortex is much larger than the traditional cortical minicolumn $\left(\sim 100 \mathrm{~s} \mu \mathrm{m}^{2}\right.$; Buxhoeveden and Casanova, 2002; Mountcastle, 2003; Rockland and Ichinohe, 2004).

Viewpoint: Neuroanatomically, an organization appears to exist where cell assemblies form intracortically in functional modules within select layers to encode perceptions.

\subsubsection{Intercortical circuit}

Intercortical circuits involve the large white matter corticocortical fiber tracts of the brain (Schmahmann and Pandya, 2006). Fiber tracts connect multiple distant cortical areas and subcortical nuclei with a great deal of specificity. The topology of corticocortical projections are the primary focus of the Human Connectome Project and CoCoMac (Kotter, 2004; Marcus et al., 2011). Contralateral corticocortical projections tend to connect the same spatial regions on opposite sides of the brain, while ipsilateral connections often connect distant areas on the same side (Barbas et al., 2005a). Different populations of pyramidal neurons tend to project contralaterally (lower layer $3 \mathrm{~b}$ ) as opposed to ipsilaterally (upper layer $3 \mathrm{a}$ and layers 5/6; Soloway et al., 2002).

We introduce a data-driven prediction for laminar projections between any two cortical areas in the human brain (Figure 3). Today, no safe experimental technique is capable of verifying laminar projections in the human. Yet by connecting and integrating previously unconnected research we arrive at very precise hypothesis with significant functional consequences in the human brain.

The cytoarchitectonics of the human cerebral cortex, as determined by von Economo, show the laminar pattern of a given area of cortex can generally fit within one of five fundamental types of cortical structure Figure 3C (von Economo, 1929; Walker, 1940). The pattern of projections between two cortical areas, as determined by Barbas in the monkey, shows a pattern of neuron layer origin and layer termination based on the difference between the two types of cortices as shown in Figure 3D (Barbas, 1986; Rockland, 1992; Barbas and Rempel-Clower, 1997; Rempel-Clower and Barbas, 2000; Barbas et al., 2005b; Van Essen, 2005; Medalla and Barbas, 2006). When von Economo and Barbas' research is aligned, as they are for the first time here, we arrive at rough laminar projection predictions between cortical areas in the human brain.

If a projection originates in a more granular (e.g., type 4, Figure 3-orange) cortical area and terminates in a less granular (e.g., type 3, Figure 3-green) cortical area, the cells of origin are predominantly in layer 3, while synaptic terminals are in layer 4 with collaterals in layers 5, 6 (feedforward projection). The majority of projections in the cerebral cortex are feedforward and originate in layers $2 / 3$. If the projection is reversed, projection neurons reside mostly in layer 5 , some in 6 , and project to layers 1 and 2 with collaterals in layer 3 (feedback projection). In visual areas, this pattern of projections has been correlated with the functional hierarchy of the cortical area (Felleman and Van Essen, 1991). The neuroanatomical architecture of a given cortical region appears to be the predictor of its functional relationship to other cortical areas.

Historical note: Barbas does not mention or cite von Economo in her papers in conjunction with the five types of cortical laminar patterns. The five types of laminar patterns in the monkey originated in 1947 when von Bonin adopted/translated von Economo's human work into the monkey (von Bonin and Bailey, 1947). Since that time, the correlation between humans and monkeys appears to have been lost in the literature. Figure $\mathbf{3}$ is designed to illustrate the correlation between the original von Economo human study and Barbas' monkey experiments performed 60 years later. The correlation adds additional significance to Barbas' original cortical projection research in the monkey (Barbas, 1986).

Viewpoint: Neuroanatomically, cell assembly to cell assembly associations form intercortically in a hierarchical layer dependent feedforward/feedback network.

\subsubsection{Cortical pyramidal layer 4 cortically projecting - C4}

Layer 4 is referred to as the inner granular layer, not for any particular cell type, but due to the visual appearance of small neurons stained in Nissl preparations. Layer 4, of all cortices, appears to be an input for feedforward type projections. In isocortex, layer 4 is the primary target of ipsilateral corticocortical feedforward cortical projections (Figure 3; DeFelipe et al., 1986; Felleman and Van Essen, 1991; Rockland, 1992; Barbas et al., 2005a; Medalla and Barbas, 2006). Since primary sensory koniocortex is the anatomically closest cortex to raw sensory input, other cortical areas can not provide feedforward input. Instead, in koniocortices, the specific thalamus provides the feedforward projection into layer 4 . In primary motor cortex layer 4 is essentially non-existent, highlighting the diminished need for feedforward input to cortical areas involved in output behavior. The cortical pyramidal neurons in layer 4, C4, typically have a descending and an ascending axon that arborize locally (<1 mm; Kritzer and Goldman-Rakic, 1995). The ascending axon reaches all supragranular layers upward of layer 2. Descending axons do not prominently exit the cortex as with most other pyramidal cells.

Only in primary sensory areas, and especially in primary visual cortex, does layer 4 contain spiny stellate cells (Meyer et al., 1989). In all other parts of cortex, spiny stellate cells are non-existent or very rare, and instead small pyramidal cells along with interneurons compose the majority of cells in L4. Quoting Lund "There are no spiny stellate neurons in V2 in contrast to area V1 where they are the main neuron types of lamina 4" (Lund et al., 1981).

Viewpoint: Neuroanatomically, C4 appears to function as a corticocortical feedforward input system.

\subsubsection{Cortical pyramidal layer 2 cortically projecting - C2}

Layer 2 is referred to as the outer granular layer because of its similar granular structure as layer 4 . The C2 neurons are small 
pyramidal neurons with local horizontal projections mostly to layer 2 and to layer 3 (Tanigawa et al., 1998; Soloway et al., 2002; Barbas et al., 2005a). Layer 2 is a primary target of ipsilateral feedback type cortical projections (Figure 3 ). The granular similarity of layer 2 to layer 4 implies a similar input architecture for feedback projections. $\mathrm{C} 2$ receives feedback input and propagates information horizontally and down to C3a and C3b, with upper layer 5 being the focus of infragranular projections (Kritzer and Goldman-Rakic, 1995).

Viewpoint: Neuroanatomically, C2 appears to function as corticocortical feedback input system.

\subsubsection{Cortical pyramidal layer 3a cortically projecting - C3a}

C3a pyramidal neurons, of typical pyramidal shape, are distinguishable from layer 2 in isocortex because of their increased size and sparsity. In layer 3 a the distance of intracortical horizontal projections increase into stripe-like patches (Lund et al., 1993; Fujita and Fujita, 1996; Melchitzky et al., 2001). C3a cells often have long horizontal projections in lower layer $3 \mathrm{~b}$ (Kritzer and GoldmanRakic, 1995). C3a cells are the dominant source of intercortical projections to layer 4 of ipsilateral cortices (Figure 3; DeFelipe et al., 1986; Rockland, 1992; Barbas et al., 2005a; Medalla and Barbas, 2006).

Viewpoint: Neuroanatomically, C3a appears to function as a corticocortical feedforward output system.

\subsubsection{Cortical pyramidal layer $5 / 6$ cortically projecting - $\mathbf{C 5 6}$}

Neurons in the lower layers of the cerebral cortex are the most diverse, but are differentiable based on the targets of their projections. We use the term C56 to group the cortical neurons in the infragranular layers of the isocortex that dominantly project corticocortically (de Lima et al., 1990; Tanigawa et al., 1998; Soloway et al., 2002). The C56 neurons often have a spindle shape and appear to lack major dendritic tufts above layer 5a (de Lima et al., 1990). The intracortical supragranular projections appear more extensive in layers 2 and 3a (Levitt et al., 1993), with distant horizontal projections in layers 5/6 (Tardif et al., 2007). The C56 group are the dominant source of intercortical projections to layer 1 and 2 of ipsilateral cortices (Figure 3; Rockland and Drash, 1996; Barbas et al., 2005a; Medalla and Barbas, 2006).

Viewpoint: Neuroanatomically, C56 appears to function as corticocortical feedback output system.

\subsubsection{Cortical interneurons}

Cortical interneurons utilize gamma-Aminobutyric acid (GABA) as an inhibitory neurotransmitter and have axonal arbors that do not exit to the white matter. The increase in cortical interneuron number and complexity of organization has long been cited by neuroanatomists as a standard feature of phylogenetic evolution, humans having the greatest number and complexity (Cajal, 2002). Interneuron organization is complex, requiring attempts to standardize terminology (Ascoli et al., 2008). Interneurons are usually first characterized by their morphology, axonal arborization, and specificity of projections. Second, interneurons are often further differentiated by calcium binding protein staining (parvalbumin, calbindin, and calretinin) and their physiological firing properties. In the human, interneurons arise developmentally from two unique genetic expression patterns corresponding to the dorsal forebrain, a cerebral cortex precursor, and the ventral forebrain, a thalamic precursor (Letinic et al., 2002). Dendritic and axonal arborization of all inhibitory neurons are less than a few $100 \mu \mathrm{m}$ in the monkey (Lund and Lewis, 1993). Inhibitory interneurons are the only known cortical neurons to form gap junctions and typically form gap junctions between the same type of interneuron (Gibson et al., 1999; Hestrin and Galarreta, 2005). Gap junctions have the property of spreading inhibition and synchronizing firing. In general, inhibitory GABAergic neurons are biased toward the upper layers of cortex. For conceptual simplicity, the dominant classes of interneurons are summarized in six neuroanatomical groupings:

1. Basket cells form the majority of interneurons, named for the basket like shape of synapses they form around the soma of pyramidal neurons (Cajal, 2002). Basket cells are typically fast spiking, parvalbumin staining, soma targeting, and have their highest densities between middle layer 3 and upper layer 5 (Lund and Lewis, 1993; Zaitsev et al., 2005). Basket cells are often further differentiated by the size and or curvature of their often long ( 100s $\mu \mathrm{m})$ horizontal axonal arborization (Lund et al., 1993; Zaitsev et al., 2009).

2. Chandelier cells are a class of axoaxonic parvalbumin inhibitory neurons which provide exclusive terminations on the initial axon segment of pyramidal neurons found mostly between layers 3 and 5 (Lund and Lewis, 1993; Conde et al., 1994; Defelipe et al., 1999). Named for the vertical chandelier look alike synaptic boutons.

3. Neurogliaform cells are small, express calbindin, and are found throughout all layers, but biased toward superficial layers with a tight dense plexus of axons (Lund and Lewis, 1993; Gabbott and Bacon, 1996; Zaitsev et al., 2005).

4. Martinotti cells express calbindin and are unique in that they send a vertically projecting axon that arborizes horizontally in layer 1 (Conde et al., 1994; Zaitsev et al., 2009).

5. Double bouquet cells express calretinin and have vertically projecting dendrites and axons that span across layers that are direct sources of inter-layer feedforward or feedback projections (Lund and Lewis, 1993; Conde et al., 1994; Zaitsev et al., 2009). Bi-tufted neurons have similar dendritic and axonal organization.

6. Cajal-Retzius cells are horizontally projecting interneurons found exclusively in layer 1 of the cerebral cortex and are the only cells found in layer 1 (Conde et al., 1994; Gabbott and Bacon, 1996; Cajal, 2002).

Viewpoint: Neuroanatomically, interneurons appear to synchronize information processing and facilitate excitatory competition through localized vertical and horizontal inhibitory projections enabling cortical information processing.

\subsubsection{Perspective on long-term declarative memory}

Our neuroanatomical perspective is that long-term memory has two distinct components, namely perceptions and associations that correlate with psychological deficits related to gray matter (intracortical) vs white matter (intercortical) lesions respectively. 
Perceptions are a form of encoding of information, while associations form relational interactions between perceptions.

Perceptions would be the result of the self-organization of different cell assemblies within a cortical module likely during prolonged (years in humans vs weeks in animals) developmental critical periods (Murphy et al., 2005). Hebb (1949) postulated that groups of neurons would form these single perceptual representations called cell assemblies. Some 56 years later, creative experiments are proving that true showing cell assembly formation in L2/3 of rat visual cortex (Yoshimura et al., 2005). The developmental temporal regulation of NMDA and GABA synaptic receptors appears to control plasticity and the formation of perceptual cell assembly representations in critical periods (Murphy et al., 2005). The long-term stability of these cell assemblies could be a direct result of the elimination of this plasticity, through for example the dramatic decrease in NMDA receptors. The spatial extent and laminar location of these cell assemblies would be defined by intracortical projections. Intracortical projections suggest that cell assemblies within a cortical module should form primarily between neurons in similar layers C3-C3, C56-C56 (Kritzer and Goldman-Rakic, 1995). Our locally distributed viewpoint of perceptions is consistent with electrophysiology evidence in the monkey (Tanaka, 2003; Tsao et al., 2006), but in direct competition with other distributed views of perceptual organization (Fuster, 2003).

The localized nature of inhibition in the cerebral cortex and the prominently local connections of excitatory pyramidal neurons onto inhibitory neurons creates an architecture sufficient for local cell assembly activity based competition. Cortical laminar organization should further aid in both the development and information processing regulation of input/output cell assembly functions.

Once perceptions stabilize within cortical modules, intercortical synaptic associations between those perceptions can form throughout life. The stability of an association would be determined by the direct corticocortical synaptic connections between the two perceptions. Presumably, if a direct corticocortical association is stable (say with fewer NMDA receptors) it would be very difficult or impossible to remove naturally. For example, the word "Brad" might exist as a stable representation in Wernicke's area, while the visual perception of facial features may exist in the fusiform face area. The simultaneous perceptions of "Brad" and "the face of Brad" could happen at any time in a persons life and may or may not be important to associate. As a consequence, the ability to temporarily store short-term associations for later consolidation to corticocortical long-term memory is necessary for the selection of stable associations. Short-term memory would presumably require an independent neuroanatomical architecture.

\subsection{SHORT-TERM DECLARATIVE MEMORY: CORTICO-HIPPOCAMPAL-CORTICAL CIRCUIT}

Psychological access to declarative memory occurs on different time-scales. Neuroanatomical evidence suggests the short-term memory system operates independently of the long-term memory system. Short-term declarative memory is defined as the declarative memory which requires the parahippocampal gyrus (periallocortex) and hippocampal (allocortex) formations for recollection (Squire, 2004). In humans, short-term memory takes weeks to years to consolidate from the periallocortex to the isocortex, wherein declarative memory is consolidated long-term (Squire and Alvarez, 1995). The localization of short-term memory to the hippocampal regions was demonstrated in patient H.M. who had no short-term memory, but retained long-term consolidated memory and behavioral/procedural memory. Due to surgical lesions, H.M. was essentially left with no allocortex or periallocortex (Milner, 2005). We can conclude that the periallocortical and hippocampal circuits are necessary neuroanatomical structures through which short-term memory is formed and later consolidated into corticocortical long-term memory (Squire and Zola, 1996; Eichenbaum, 2000; Squire, 2004).

\subsubsection{Parahippocampal gyrus/periallocortex - PH}

The parahippocampal gyrus, also called periallocortex because of its transitional laminar structure between isocortex and allocortex, consists of the entorhinal and perirhinal cortices. A reciprocal topographic connectivity exists between association isocortices and periallocortices that are well mapped, but the actual specificity of laminar projections remains vague at best (Witter et al., 1989; Burwell, 2000; Lavenex et al., 2002). The periallocortex contains intralayer connectivity similar to regular isocortex with less laminar differentiation. The periallocortex is the neuronal interface between the isocortex and the hippocampus, since the isocortex does not typically project directly to the hippocampus. The afferent input and efferent output of the periallocortex can grossly be split into upper ( $\mathrm{PH} 23$ ) and lower (PH56) layers respectively based on its projections with the isocortex and allocortex. To a lesser degree, the periallocortex receives subcortical input from the amygdala, claustrum, basal forebrain, thalamus, hypothalamus, and brainstem (Insausti et al., 1987).

- $\mathrm{PH} 23$ is used to describe the upper layers in the periallocortex that receive afferent projections from the isocortex (typically C3b; Witter et al., 1989). Input to PH23 is topographically organized and dominated by multimodal association isocortex (Burwell, 2000). PH23 sends efferent projections to the hippocampus.

- PH56 is used to describe the lower layers in the periallocortex that send efferent projections to the isocortex with origin/target laminar distributions similar to intercortical association projections (Figure 3; Witter et al., 1989). PH56 generally projects back topographically in a reciprocal manner to multimodal association isocortex (Lavenex et al., 2002). PH56 receives afferent projections from the hippocampus.

The aggregate evidence suggests that $\mathrm{C} 3 \mathrm{~b}$ (and some C56) cells project to $\mathrm{PH} 23$ and receive reciprocal projections back from the PH56 regions to which they projected, but far more detailed studies are necessary.

Viewpoint: Neuroanatomically, the periallocortex appears to facilitate medium-term storage of associations, temporally acting between short-term and long-term memory, capable of mapping source $\mathrm{C} 3 \mathrm{~b}$ representations to target $\mathrm{C} 3 \mathrm{~b}$ representations in the isocortex. 


\subsubsection{Cortical pyramidal layer $\mathbf{3 b}$ cortically projecting - C3b}

Lower layer $3 \mathrm{~b}$ in the isocortex is centrally located to be the hub of perceptual information processing in the cerebral cortex. The large pyramidal neurons located in the lower part of layer 3, just above the granular layer 4 could be included in multiple circuits including long-term memory, working memory/information processing, and behavior output. The $\mathrm{C} 3 \mathrm{~b}$ cells have the classic pyramidal neuron shape and are usually the second largest pyramidal neuron group next to C5p (Jones and Wise, 1977; Rempel-Clower and Barbas, 2000; Barbas et al., 2005a). The C3b intracortical projections involve some of the longest (many millimeters) gray matter projections in the cerebral cortex (Kritzer and Goldman-Rakic, 1995; Fujita and Fujita, 1996; DeFelipe, 1997). The horizontal projections form stripe-like vertical patches and have all the same qualities described in the C3a group.

In the isocortex, different populations of pyramidal neurons tend to project contralaterally as opposed to ipsilaterally. The contralateral projections arise mostly from $\mathrm{C} 3 \mathrm{~b}$ cells and target the spatially analogous region of cortex on the other side of the brain, while ipsilateral projections mainly arise from C3a and C56 (Soloway et al., 2002). The same C3b and C56 cells appear to be the dominant source of isocortex $\rightarrow$ periallocortex projections (Witter et al., 1989; Burwell, 2000), responsible for communicating representations in the isocortex to the hippocampus for association.

The C3b cells appear to preferentially stain for acetylcholine with C5p cells (Voytko et al., 1992; Hackett et al., 2001), and have been shown to have preferential connections with C5p cells (Thomson and Bannister, 1998; Briggs and Callaway, 2005). In the agranular primary motor cortex, all layers visually look like a combination of $\mathrm{C} 3 \mathrm{~b}$ and $\mathrm{C} 5 \mathrm{p}$ cells of various sizes.

Historical note: In 1949, Lorente de No referred to the large cells above the granular layer as "star pyramids" and called the location "layer 4a" (Lorente de No, 1943). Today, the same cells are typically referred to as large pyramidal neurons in layer $3 \mathrm{~b}$. The usage of the terms "star" and "layer 4" to describe these cells appears to have caused subtle confusion throughout the years, including the target layer of specific thalamocortical projections. The confusion arises due to the modern descriptions of "stellate" cells in "layer $4 \alpha$ " or " $4 \beta$ " of primary visual cortex.

Viewpoint: Neuroanatomically, C3b appears to function as stable invariant perceptual representations in the cerebral cortex that are associated in short-term memory.

\subsubsection{Hippocampus/allocortex}

The hippocampus proper, called allocortex due to its lack of lamination and different appearance from isocortex, is a full circuit in and of itself (Amaral and Witter, 1989). The hippocampus is functionally dominated by the dentate gyrus (DG), CA3 fields, CA1 fields, and subiculum (Sb). A simplified feedforward picture shows the projection circuit loop as: isocortex $\rightarrow \mathrm{PH} 23 \rightarrow$ Dentate Gyrus $\rightarrow$ CA3 $\rightarrow$ CA1 $\rightarrow$ Subiculum $\rightarrow$ PH56 $\rightarrow$ isocortex. Multiple feedback connections exist within this path (Amaral and Witter, 1989). The DG and olfactory bulb/subventricular zone are the only widely accepted brain structures consistently shown to contain adult neurogenesis (the new production of neurons) in the non-damaged primate brain (Gould, 2007). Thehippocampus essentially receives all the same subcortical input as parahippocampal cortex described above (Amaral and Cowan, 1980).

Viewpoint: Neuroanatomically, the hippocampus appears to associate perceptions in the isocortex through mapped representations in periallocortex based upon emotional context.

\subsubsection{Perspective on short-term declarative memory}

Our neuroanatomical perspective on the perihippocampal cortex and hippocampus are that they function to temporarily store short-term associations between isocortical perceptions that can later be consolidated into direct corticocortical long-term memory associations. The subcortical input to the peri-/allocortex being part of the emotional system would imply that the creation of associations is largely influenced by emotional significance. The functional flow of short-term memory information would appear to involve (see also Figures 4 and 5):

- Association (cortical area A and B) - active C3b perceptions in area $\mathrm{A}$ and $\mathrm{B} \rightarrow$ activation $\mathrm{PH} 23 \mathrm{~A}$ and $\mathrm{B} \rightarrow$ binding in hippocampus. Additionally, $\mathrm{PH} 23 \mathrm{~A}$ and $\mathrm{B} \rightarrow \mathrm{PH} 56 \mathrm{~A}$ and $\mathrm{B}$ activations.

- Recall - active $\mathrm{C} 3 \mathrm{~b}$ perception in area $\mathrm{A} \rightarrow \mathrm{PH} 23$ area $\mathrm{A} \rightarrow$ unbinding in hippocampus $\rightarrow$ PH56 area $\mathrm{B} \rightarrow$ active $\mathrm{C} 3 \mathrm{~b}$ perception area B.

- Alternate recall - active $\mathrm{C} 3 \mathrm{~b}$ perceptions in area $\mathrm{A} \rightarrow \mathrm{PH} 23$ area $\mathrm{A} \rightarrow \mathrm{PH} 56$ area $\mathrm{B} \rightarrow$ active $\mathrm{C} 3 \mathrm{~b}$ perception area $\mathrm{B}$.

The idea of stable perceptions in the isocortex being associated in the hippocampus is consistent with the hippocampal indexing theory of episodic memory (Teyler and Rudy, 2007). The consolidation of indirect hippocampal short-term memory associations into direct corticocortical long-term memory associations involves the reactivation of short-term memory associations during sleep (O’Neill et al., 2010).

Historical note: A curious, rarely talked about cortical region next to the periallocortex and allocortex is the granulous retrosplenial (Rsc) cortex [von Economo area LE; Brodmann area 29]. The Rsc has laminar differentiation representative of primary sensory koniocortex and significant reciprocal projections with allo-/periallocortex and prefrontal cortex (Kobayashi and Amaral, 2003, 2007). Thus, Rsc could potentially be viewed as "primary memory cortex."

\subsection{WORKING MEMORY/INFORMATION PROCESSING: CORTICO-THALAMOCORTICAL CIRCUIT}

The definition of working memory is adopted from Monsell as "no more (or less) than a heterogeneous array of independent temporary storage capacities intrinsic to various subsystems specialized for processing in specific domains" (Monsell, 1984). Working memory operates on the time-scale at which attention can be maintained, seconds to minutes (Baddeley, 1981; Monsell, 1984). Experiments typically require participants to hold digits, numbers, or words in memory for future recall and measure the number of elements capably held in working memory (usually between 4 and 7 items). Monsell's definition is consistent with a localized neuroanatomical information processing architecture. We use the term information processing to describe the dynamic activation of perceptions 
described by Monsell's “independent. . .subsystems. . .processing in specific domains."

Exactly how information is processed in the brain is still an open question. However, information processing in the brain has been correlated with various brain wave oscillations (Buzsaki, 2006). Synchronized information processing across distributed regions of primate cortex has been correlated with low gamma (25-60 Hz; Knight, 2007). Cortical electrophysiology recordings of humans undergoing neurosurgery also include distinct localized high gamma $(80-160 \mathrm{~Hz})$ frequencies during speech tasks (Edwards et al., 2005; Canolty et al., 2006).

States of being awake or asleep are definitive indicators of information processing in the brain, and interactions in the thalamus are highly correlated in the transition from sleep to wakefulness, and for correlations between gamma and slower oscillations (Steriade, 2006).

The interactions between the thalamus and cerebral cortex are therefore essential in gaining understanding into working memory and information processing.

\subsubsection{Thalamus}

The thalamus has a uniform organization and highly stereotyped reciprocal projections with the cerebral cortex. For the interested reader, the thalamic bible written by the late Jones (2007) is unparalleled in its descriptive depth of the thalamus. The thalamus is composed of multiple nuclei that can be identified histologically and by the source/target of their afferent/efferent projections (Macchi and Jones, 1997). The general organization of the thalamus leads us to divide the thalamus into three homotypical types: specific (Ts), intralaminar ( $\mathrm{Ti}$ ), and layer 1 projecting (TL1). The division into three types of thalamic projections is novel and imparts a functional perspective to the target laminar location of thalamic neurons. Although thalamic neurons undoubtedly project to multiple layers, usually via collateral projections, the first-order homotypical architecture of thalamic laminar projections warrants a division into three distinct (source thalamus target cortical layer) combinations: Ts - layers 3/4, Ti - layers 5/6, and TL1 - layer 1 . For the present circuit we only discuss the Ts projection.

\subsubsection{Specific thalamus - Ts}

Specific thalamic neurons project to the mid layers in the cerebral cortex. Ts thalamocortical projections are to lower layer $3 \mathrm{~b}$ in primate isocortex, often avoiding layer 4 (Jones and Burton, 1976; Trojanowski and Jacobson, 1976; Giguere and Goldman-Rakic, 1988; Romanski et al., 1997; Rockland et al., 1999; McFarland and Haber, 2002; Jones, 2007), while only koniocortical projections are to layer 4 (Callaway, 1998). The Ts thalamocortical projection is localized $\left(<\mathrm{a}\right.$ few $\mathrm{mm}^{2}$ ) and topologically organized in the cerebral cortex in accordance with the temporal development of projections (Kievit and Kuypers, 1977; Goldman-Rakic and Porrino, 1985; Baleydier and Mauguiere, 1987; Vogt et al., 1987; Brysch et al., 1990; Hohl-Abrahao and Creutzfeldt, 1991).

Historical note: The early work by Cajal and Lorente de No, along with the disproportionate amount of research dedicated to primary sensory areas, appears to have ingrained layer 4 as the generally taught location of specific thalamocortical projections. The notion that the Ts thalamocortical projections terminate in layer 4 must be updated throughout the neuroscience world to differentiate between koniocortex layer 4 and isocortex layer $3 \mathrm{~b}$ terminations. As Ted Jones says "Outside these areas [koniocortex]... thalamic fibers tend to avoid layer IV and terminate almost completely in the deeper half of layer III." p. 95 (Jones, 2007).

The Ts is composed of multiple histologically identifiable subnuclei that can be further subdivided based on afferent/efferent projections. We functionally separate the non-primary Ts into two main groups and adhere to Jones (2007) terminology. The ventral group is composed of the ventral anterior (VA) and ventral lateral (VL) nuclei. VA and VL (having subdivisions themselves; Macchi and Jones, 1997) generally project to the behavioral parts of the brain related to thinking (frontal cortex) and movement (motor cortex) respectively. We separate the ventral group from other Ts nuclei because of the afferent projections from the basal ganglia (Sidibe et al., 1997; Parent and Parent, 2004) and cerebellum (Sakai et al., 1996; Hamani et al., 2006), both involved in controlling thinking and movement. The second non-primary Ts group of nuclei are composed of nuclei related to more sensory (as opposed to behavioral) regions of the brain. The pulvinar (P) and lateral posterior (LP) nuclei can be generally grouped (anatomically/functionally) and largely project to temporal and parietal isocortex. The anterior (A) and the lateral dorsal (LD) complex can be similarly grouped and are largely connected to cingular and retrosplenial cortex. Note the challenges in nuclei naming conventions, e.g., the lateral nuclei not being grouped together.

Viewpoint: Neuroanatomically, the specific thalamus appears to drive the convergent reentrant selection of $\mathrm{C} 3 \mathrm{~b}$ and C6t perceptual representations in cortico-thalamocortical oscillations.

\subsubsection{Cortical pyramidal layer 6 thalamic projecting - C6t}

Cortical C6t cells have a neuroanatomical organization highly linked to Ts projections. C6t cells send both apical dendrite and intracortical axon projections to layer $3 \mathrm{~b}$ in the isocortex (Jones and Wise, 1977; Lund et al., 1981; Peters et al., 1997; Rockland and Ichinohe, 2004) and layer 4 in koniocortex (Briggs and Callaway, 2001). The C6t cell projections leaving the cortex target local regions of the Ts in a reciprocal manner (Trojanowski and Jacobson, 1977; Catsman-Berrevoets and Kuypers, 1978; Asanuma et al., 1985; Giguere and Goldman-Rakic, 1988; McFarland and Haber, 2002). Note the anatomical reentrant blueprint specifying that C6t intracortical axons/dendrites target the same cortical layer receiving Ts projections.

Viewpoint: Neuroanatomically, C6t appears to function in conjunction with $\mathrm{C} 3 \mathrm{~b}$ and $\mathrm{Ts}$ to facilitate cortico-thalamocortical oscillations.

\subsubsection{Thalamic reticular nucleus - TRN}

The TRN is a thin shell of GABAergic neurons surrounding the entire thalamus (Scheibel and Scheibel, 1966). The majority of TRN afferent connections arise from ascending Ts and descending C6t projections (Jones, 1975). Different sizes of axonal boutons (small and large) in the TRN have been correlated with source cortical topology and layer (L6 and L5) respectively (Zikopoulos and Barbas, 2006). The TRN then projects directly onto the Ts in an inhibitory manner (Scheibel and Scheibel, 1966; Velayos et al., 
1989). Other projections to the TRN include cholinergic projections from the brainstem as shown in the cat (Pare et al., 1988) and GABAergic projections from the basal ganglia GPe in the monkey targeting the ventral thalamic region (Asanuma, 1994).

Viewpoint: Neuroanatomically, the TRN appears to function in gating thalamocortical information to regulate cognitive states.

\subsubsection{Perspective on working memory and information processing} Our neuroanatomical viewpoint is that working memory and associated gamma frequency information processing is the result of attentionality directed cortico-thalamocortical oscillations. We hypothesize that information processing involves the competitive selection (activation) of perceptions (cell assemblies) driven by the $\mathrm{Ts} \rightarrow \mathrm{C} 3 \mathrm{~b} \rightarrow \mathrm{C} 6 \mathrm{t} \rightarrow \mathrm{Ts}$ circuit. Working memory would involve the maintenance of active perceptions in each localized thalamocortical loop, explaining both the distributed nature of working memory, the constraints on the number of items stored, the need for attention, and the competitive interaction between domain specific information. The source and mechanism of attentional control are highlighted in the control circuit.

Additional neuroanatomical evidence is consistent with our hypothesis. In the human, the distance between the cerebral cortex and the thalamus is approximately $20-50 \mathrm{~mm}$ (Nolte and Angevine, 2000). Typical conduction velocities throughout the brain might be regulated from 1 to $50 \mathrm{~mm} / \mathrm{ms}$ depending on myelination (Kimura and Itami, 2009). Human thalamocortical conduction velocity has been estimated at $29 \mathrm{~mm} / \mathrm{ms}$ (Kimura et al., 2008). The cortico-thalamocortical physical distances combined with conduction velocity and short delays in neuronal firing (1-8 ms) are consistent with a circuit level cortico-thalamocortical reentrant explanation for gamma frequency information processing oscillations in the brain. Spiking neuroanatomical models have been built supporting our hypothesis (Solari, 2009). This is in contrast to most other models of working memory that have focused on intrinsic properties of interneurons or intracortical activity without regard to the thalamus (Compte et al., 2000; Durstewitz et al., 2000; Brunel and Wang, 2001).

\subsection{BEHAVIORAL MEMORY ACTION SELECTION: CORTICO-BASAL GANGLIA-THALAMOCORTICAL CIRCUIT}

In contrast to declarative memory other psychological evidence highlights memory systems more highly involved in the learning of actions and behaviors. We utilize Squire's description that "[procedural memory] is expressed through performance rather than recollection... the memories are revealed through reactivation of the systems within which the learning originally occurred" (Squire, 2004). A distinguishing feature of procedural memory is that through practice and repetition, behavioral memories (i.e., actions) can be learned and executed without declarative recall of how the action was learned. Another term often used is skill learning. We use the term behavioral memory to include all behavioral actions generated by homotypical circuits including externally measurable procedural memory and internal procedural thought processes. Behavioral memory systems have been elucidated in patients like H.M., patients with Alzheimer's and in patients with Parkinson's and Huntington's disease (Heindel et al., 1989). For example, the behavioral effects of Parkinson's disease typically progress from motor movement rigidity, postural instability and tremor to cognitive apathy and diminished novelty seeking (Lauterbach, 2005). Huntington's disease on the other hand typically begins with chorea (initiated dance-like movements that flow from start to finish without stopping) and progress to cognitive dysfunctions impairing organizing, planning, or adapting alternatives (Walker, 2007). Parkinson's and Huntington's disease both involve degeneration of different parts of the basal ganglia, highlighting the role of the basal ganglia in behavior selection. The basal ganglia is highly involved in the action based reward system through increases and decreases in dopamine (Bromberg-Martin et al., 2010).

\subsubsection{Basal ganglia}

The basal ganglia is a structure that is essential for learning and coordination in movement and cognition (Doya, 1999; Benke et al., 2003; Lauterbach, 2005; Van Essen, 2005). The basal ganglia is composed of multiple subnuclei. The historical naming of the basal ganglia does not make the homotypical groupings intuitive. The striatum, containing GABAergic projection neurons, is the dominant input structure and is comprised of the putamen, caudate, and nucleus accumbens (also called the ventral striatum). The globus pallidus external segment (Gpe), referred to only as the globus pallidus in the mouse, dominates the internal circuitry of the basal ganglia. The globus pallidus internal segment (Gpi) and substantia nigra pars reticulata (Snr) form a spatially disjoint but functionally singular GABAergic output structure of the basal ganglia (Gpi/Snr). The subthalamic nucleus (Stn) provides glutamatergic excitatory input to multiple elements in the basal ganglia. The substantia nigra pars compacta (Snc) provides dopaminergic input to the striatum, the damage of which is the source of Parkinson disease. Huntington's disease involves the degeneration of the striatum progressing from motor (putamen) to cognitive (caudate) deficits (degeneration; Heindel et al., 1989). The same correlations between motor/cognitive deficits and putamen/caudate dysfunction is found in Parkinson's (Lauterbach, 2005).

The projections through the basal ganglia are organized into parallel, yet overlapped pathways from the entire isocortex (Smith et al., 1998, 2004) forming a homotypical architecture. Primary auditory and visual cortex are the only cortices that do not project to the basal ganglia in the monkey (Borgmann and Jurgens, 1999). Most nuclei in the basal ganglia rely on GABA as a neurotransmitter forming a consistent disinhibitory functional pathway. The GABAergic neurons in the basal ganglia are inherently tonically active and do not require input to continually fire action potentials. Based on neuron number, a significant amount of neural convergence occurs from input to output through the basal ganglia. The human and rat striatum have about $70 \mathrm{M}$ and $2.8 \mathrm{M}$ neurons respectively (Oorschot, 1996; Kreczmanski et al., 2007). In both species the number of neurons decrease approximately 50 to 1 (striatum $\rightarrow$ Gpe) and 2 to 1 (Gpe $\rightarrow$ Gpi/Snr; Oorschot, 1996; Hardman et al., 2002), resulting in a 100 to 1 neural convergence of basal ganglia input to output.

Several excellent reviews of the basal ganglia and dopamine system exist (Herrero et al., 2002; Haber, 2003; Lee and Tepper, 2009; Gerfen and Surmeier, 2010). 


\subsubsection{Striatum matrix and patch $-\mathrm{Sm}$ and $\mathrm{Sp}$}

The striatum can be divided into histologically defined compartments called the matrix (matrisome) and patch (striosome). Among other factors, the matrix compartments have high cholinesterase activity, while patches are enriched in enkephalin (i.e., endorphins; Gerfen, 1984). The striatum contains multiple interneurons containing both GABA and acetylcholine forming distinct intrastriatal networks (Kawaguchi et al., 1995).

The matrix compartments of the striatum receive projections from C5s neurons across the entire isocortex (Jones et al., 1977; Arikuni and Kubota, 1986; Kunishio and Haber, 1994; Yeterian and Pandya, 1994). The cortical projections are topographically mapped (Alexander et al., 1986). In general the striatum receives reciprocal projections back from the thalamic nuclei that it projects to. The intralaminar thalamus projects topographically onto the striatum with the rough order $\mathrm{CM} \rightarrow$ putamen, $\mathrm{PF} \rightarrow$ caudate, midline $\rightarrow$ ventral striatum (Sadikot et al., 1992a,b; Tande et al., 2006). The ventral thalamus also projects back onto the striatum (McFarland and Haber, 2001).

- SmD1 neurons are GABAergic spiny projection neurons found within the matrix portion of the striatum that express dopamine D1 receptors. The effect of dopamine on SmD1 neurons increases excitability (Surmeier et al., 2007). SmD1 is traditionally considered part of the direct pathway through the basal ganglia because of its projections to Gpi/Snr (Levesque and Parent, 2005b). The projection is topographically maintained from the striatum to Gpi/Snr (Haber et al., 1990).

- SmD2 neurons are GABAergic spiny projection neurons found within the matrix portion of the striatum that express dopamine D2 receptors. The effect of dopamine on SmD2 neurons decreases excitability (Surmeier et al., 2007). SmD2 is traditionally considered part of the indirect pathway through the basal ganglia because of its projections to the Gpe (Haber et al., 1990; Levesque and Parent, 2005b).

- Sp neurons are GABAergic spiny projection neurons found in the patches of the striatum and project prominently to the Snc (Haber et al., 1990; Fujiyama et al., 2011). The Sp send smaller numbers of axon collaterals into the Gpe and Gpi/Snr (Levesque and Parent, 2005b). In contrast to the matrix, the patch compartments receive their input from C5p neurons in the isocortex (Gerfen, 1984, 1989).

Viewpoint: Neuroanatomically, SmD1 appears as a C5s cortically evoked start action mapping through the disinhibitory direct pathway SmD1 $\rightarrow$ Gpi/Snr learned from positive dopamine reinforcement. SmD2 appears as a C5s cortically evoked stop action mapping through the dual disinhibitory-disinhibitory indirect pathway SmD2 $\rightarrow$ Gpe $\rightarrow$ Gpi/Snr or the feedback pathway $\mathrm{SmD} 2 \rightarrow \mathrm{Gpe} \rightarrow \mathrm{SmD} 1$ learned from negative dopamine reinforcement. Sp appears as a C5p cortically evoked dopamine based learning signal via the $\mathrm{Sp} \rightarrow$ Snc pathway in order to reinforce the two Sm pathways.

\subsubsection{Globus pallidus external segment - Gpe}

The Gpe neurons are GABAergic neurons that primarily receive inhibitory projections from the $\mathrm{SmD} 2$ portion of the striatum
(Haber et al., 1990; Levesque and Parent, 2005b) and excitatory projections from the STN (Parent et al., 1989; Nambu et al., 2000). Gpe neurons project onto the Gpi/Snr, Stn, and send feedback connections onto the matrix portion of the striatum (Sato et al., 2000).

A potentially significant but rarely mentioned projection is the Gpe projection to the TRN of the ventral thalamus (Hazrati and Parent, 1991b; Gandia et al., 1993; Asanuma, 1994). Since the TRN provides inhibitory input to the thalamus, the Gpe projection to the TRN might be functionally analogous to the Gpe projection to the inhibitory Gpi/Snr that then projects onto the thalamus.

\subsubsection{Globus pallidus internal segment/substantia nigra pars reticulata - Gpi/Snr}

The Gpi/Snr is the source of the major GABAergic output from the basal ganglia. The Gpi and Snr are physically separated nuclei, with the Snr located adjacent to the Snc (hence the naming convention). However, from a neuroanatomical perspective these structures are functionally equivalent. The Gpi/Snr receives afferent input from all other basal ganglia nuclei, including the matrix striatum (Haber et al., 1990; Levesque and Parent, 2005b), the Gpe (Sato et al., 2000), the STN (Levesque and Parent, 2005a), and collateral projections from the Snc (Charara and Parent, 1994; Zhou et al., 2009).

The Gpi/Snr is tonically active (Zhou et al., 2009) and projects onto the intralaminar thalamus in a topographic pattern (Parent et al., 2001; Sidibe et al., 2002; Parent and Parent, 2004). The Gpi/Snr also send significant projections onto the ventral thalamus including TL1 (Hazrati and Parent, 1991a; Sidibe et al., 1997).

Viewpoint: Neuroanatomically, the Gpi/Snr appears to perform precise temporal action triggering in the intralaminar and ventral thalamus through disinhibition.

\subsubsection{Subthalamic nucleus - STN}

The STN is the only excitatory nucleus in the basal ganglia and utilizes glutamate as a neurotransmitter. The STN appears to receive an excitatory topographically mapped isocortical afferent input from C5p neurons (Nambu et al., 2000; Parent and Parent, 2006) as well as inhibitory input from the Gpe (Sato et al., 2000). The STN projects prominently onto the Gpi/Snr and to the Gpe (Parent et al., 1989; Nambu et al., 2000). The STN also contains inhibitory GABAergic interneurons (Levesque and Parent, 2005a).

Viewpoint: Neuroanatomically, the STN appears to provide a direct cortical mechanism to stop action triggering in the intralaminar thalamus through exciting the Gpi/Snr. A contrary hypothesis might suggest that the STN "prepares" desired output actions in Ti through increased inhibitory stimulation by the Gpi/Snr biasing future inhibitory rebound spikes.

\subsubsection{Substantia nigra pars compacta - Snc}

The Snc is the source of dopaminergic projections in the basal ganglia. The Snc receives its major afferent input from the patch compartments in the striatum (Gerfen, 1984; Fujiyama et al., 2011). The Snc is tonically active and receives additional inhibitory input from virtually all other structures in the basal ganglia (Lee and Tepper, 2009). The Snc projects onto the matrix compartment of the striatum (Langer and Graybiel, 1989; Matsuda et al., 2009; Gerfen and Surmeier, 2010). 
Viewpoint: Neuroanatomically, the Snc appears to provide a differential dopamine reward signal to the striatum to learn start and stop action sequences.

\subsubsection{Intralaminar thalamus - Ti}

The intralaminar thalamus is composed of the center median (CM), parafascicular (PF), and midline nuclei (Jones, 2007). The midline nuclei are usually further subdivided into the central medial, paracentral, central lateral, and rhomboid nuclei. The intralaminar nuclei output topographic projections to both the striatum and to the lower layers of the isocortex (Brysch et al., 1984; Sadikot et al., 1992a,b; Tande et al., 2006). In a gross topographic organization, $\mathrm{PF}$ is associated with frontal cortex and the caudate, CM with motor cortex and the putamen, and midline with cingular cortex and the nucleus accumbens. Ti projects dominantly to lower layers $5 / 6$ in the cerebral cortex (Herkenham, 1980). The most compelling evidence confirming this fact in primates comes from single-axon tracing studies in the monkey that undeniably demonstrate the majority of intralaminar $(\mathrm{CM} / \mathrm{PF})$ projections principally terminate in layers $5 / 6$ with fewer collateral projections to layer 1 (Parent and Parent, 2005). The Ti nuclei projections are largely segregated into those that project exclusively to the cerebral cortex and those that project to the matrix portion of the striatum (Parent and Parent, 2005).

Historical note: The intralaminar nuclei of the thalamus were originally thought to provide the majority of the "non-specific" diffuse layer 1 input in the cerebral cortex identified by Lorente de No in the 1940s (Lorente de No, 1943). In the 1950s, research focused on understanding the cortical "recruiting response" due to intralaminar electrode stimulation (Hanbery and Jasper, 1953, 1954). The recruiting response (most studied in cats) requires pulsed thalamic stimulation of 3-10 Hz (Verzeano et al., 1953). After tens of milliseconds, strong surface negative wave potentials would appear across widespread cortical areas. The widespread nature of the recruiting response was attributed to the thalamocortical layer 1 projections described by Lorente de No. The measured recruiting response is more widespread than Ts stimulation but topographically organized, which is consistent with the intralaminar topographic projection. Today, a more anatomically consistent viewpoint is that the recruiting response involves Ti-C5s-basal ganglia-Ti and/or Ti-basal ganglia-Ti-cortical circuits that prominently involve the lower layers of the cerebral cortex rather than layer 1. Future experiments are necessary for any definitive conclusion.

Viewpoint: Neuroanatomically, the intralaminar thalamus appears to excite the behavioral output of the lower layers of the cerebral cortex to accurately select C5p output and drive cortically evoked behaviors.

\subsubsection{Cortical pyramidal layer 5 striatally projecting - C5s}

$\mathrm{C} 5 \mathrm{~s}$ are pyramidal neurons in the isocortex that principally project to the striatum. C5s pyramidal neurons are typically located in the upper portion of layer 5, L5a, with a prominent ascending dendrite that arborizes in L1 (Jones et al., 1977; Arikuni and Kubota, 1986; Yeterian and Pandya, 1994). C5s send projections to the matrix portion of the striatum (Jones and Wise, 1977; Gerfen, 1989; Parent and Parent, 2006). C5s neurons are likely the source of cortical projections to $\mathrm{Ti}$ that are distinct from C6t projections in the monkey (Catsman-Berrevoets and Kuypers, 1978) and cat (Kakei et al., 2001). C6t thalamic terminations are small and dense, while C5s synaptic terminals are large and sparse (Rouiller and Durif, 2004). The large terminals found in the TRN are likely a result of C5s collaterals (Zikopoulos and Barbas, 2006). In the rat, $\mathrm{C} 5 \mathrm{~s}$ and $\mathrm{C} 5 \mathrm{p}$ neurons have been shown to be distinct populations (Levesque et al., 1996; Molnar and Cheung, 2006), with C5s having a higher probability of recurrent $\mathrm{C} 5 \mathrm{~s} \rightarrow \mathrm{C} 5 \mathrm{~s}$ connections (Morishima and Kawaguchi, 2006). L5a intracortical projections have distant $\sim 1-2 \mathrm{~mm}$ projections in layers $2 / 3 \mathrm{a}$, and slightly longer projections within the same layer 5a (Levitt et al., 1993; Kritzer and Goldman-Rakic, 1995).

Viewpoint: Neuroanatomically, C5s appears to encode suggested action sequences within a cortical module for selection in the basal ganglia.

\subsubsection{Perspective on behavioral memory action selection}

The basal ganglia receives topographic projections from the entire isocortex, which has lead to the notion of separate functional loops through the basal ganglia (Smith et al., 1998, 2004; Haber, 2003). We differ in our assessment of the anatomical facts and hypothesize that the pathway through the basal ganglia has a single uniform function, with the only difference being the cortical source of information that is operated on. Functionally, the output from the Gpi/Snr to the thalamus is tonically inhibitory. Therefore, processing in the basal ganglia ultimately results in disinhibition of the thalamus for causal effect. One view of disinhibition is allowing target neurons to be excited. Another view of disinhibition is causing neurons to fire precise rebound spikes as a result of release from inhibition (Grenier et al., 1998). The evidence suggests that the basal ganglia is responsible for learning to select sequences of precise on/off action triggering (Bottjer, 2005). The evolution of the coordinated control of muscles and muscle groups in early ancestral vertebrates requires this exact on/off mechanism of learning. A hierarchical information structure, like the cerebral cortex and topographic striatal mapping, operating at different time-scales would enable enormous combinatorial flexibility of cognitive behavior just as with movement.

If the basal ganglia is responsible for action selection, then the near 100 to 1 neural convergence from the striatum to the Gpi/Snr complex implies a reduced set of output action possibilities compared to input action suggestions. The basal ganglia is likely capable of storing temporally sequenced actions (or cortical locations) through its internal circuitry. In this case, the 100 to 1 convergence may serve to encode temporal sequences of actions represented by $\mathrm{C} 5 \mathrm{~s}$ that are translated into disinhibition of singular actions in Ti in a sequential manner. The utilization of two prominent dopamine systems, D1 and D2, would serve to encode coupled starting and stopping actions respectively (Apicella, 2007). The increase (reward) or decrease (anti-reward) of dopamine would then serve to reinforce start and stop sequences.

The projection from the cerebral cortex C5p neurons to the patch portion of the striatum is significant because of the indirect effect on dopamine release via the Snc. The same C5p neurons appear to project to the STN, creating a significant path of primarily stopping actions (increased activity of STN), while simultaneously generating an anti-reward signal (increased inhibition of the Snc) to prevent that same future behavior. 


\subsection{BEHAVIORAL MEMORY OUTPUT: CORTICO-PONTINE (CORTICO-SUBCORTICAL) CIRCUIT}

Behavior involves not only an organisms externally observable movement, but also its internal cognitive processes. During evolution, the same circuits that regulated muscles through the spinal chord in early vertebrates were re-directed to target internal brain structures (Striedter, 2005). We focus here on neuronal groups known to be involved in behavioral movement and their parallel internal connectivity presumably involved in behavioral cognitive processes.

In all vertebrates, motor neurons in the spinal chord project acetylcholine onto muscles to make them contract (Lieber, 2002; Striedter, 2005). In higher mammals projections from large neurons in lower layer 5 (C5p) of primary motor cortex directly target alpha-motor neurons in the spinal chord (Stanfield, 1992). Lesions to primary motor cortex in the human cause complete paralysis of the body associated with the cortical lesion (Penfield and Rasmussen, 1968).

To neuroanatomically understand behavioral output, we focus on the C5p neuron and the correlates to acetylcholine systems in the brain that appear to be phylogenetically involved in movement.

\subsubsection{Cortical pyramidal layer 5 pons projecting - C5p}

The C5p population refers to the collection of primarily pons (and other subcortically) projecting pyramidal cells found throughout the entire isocortex (Hackett et al., 2001; Watakabe et al., 2007). C5p neurons are located in layer 5b (Foster et al., 1981), have large dendritic tufts in layer 1 , and are distinct from C5s neurons (Molnar and Cheung, 2006; Morishima and Kawaguchi, 2006). The C5p intracortical projections are not extensive, often restricted to short distances in layer 5 (Ghosh and Porter, 1988), however their dendritic arborization is quite large. Generally, the largest neurons in the isocortex are C5p neurons and in primary motor cortex C5p neurons are referred as large Betz cells (Braak and Braak, 1976). Since the majority of C5p neurons target the pons (relaying information to the cerebellum), we suggest that the cognitive function of C5p neurons may be inferred through analogy with Betz cells in primary motor cortex. The projections from C5p neurons in primary motor cortex synapse directly with the spinal chord causing physical movement (Stanfield, 1992). The direct projection to the spinal chord is weak in lower mammals, but becomes increasingly prominent in primates, and presumably dominates in humans, suggesting an increasingly more direct cortical involvement in behavior (Lemon and Griffiths, 2005). C5p projections from frontal cortex target the STN of the basal ganglia with collaterals to the striatum (Nambu et al., 2000; Parent and Parent, 2006). Evidence suggests that C5p striatal projections target the Sp patch (striosome) portion of the striatum that projects to the dopamine filled Snc (Gerfen, 1984, 1989).

The origin of C5p afferent input should provide a clue to the synaptic organization of cognitive and physical behavior memory output throughout the brain. A synaptic relationship exists between $\mathrm{C} 3 \mathrm{~b}$ and $\mathrm{C} 5 \mathrm{p}$ neuronal groups because of a preference for direct synaptic connections from $\mathrm{C} 3 \mathrm{~b}$ to $\mathrm{C} 5 \mathrm{p}$ neurons potentially related to basal forebrain acetylcholine activity (Thomson and Deuchars, 1997; Thomson and Bannister, 1998; Kaneko et al., 2000).
Viewpoint: Neuroanatomically, C5p neurons appear to form the physical and cognitive behavioral output of the cerebral cortex.

\subsubsection{Basal forebrain - BF}

Acetylcholine is found in primarily three populations of neurons in the brain: alpha-motor neurons, interneurons in the striatum, and the basal forebrain including the nucleus of Meynert (Satoh and Fibiger, 1985). Basal forebrain lesions "abolish cortical plasticity associated with motor skill learning" (Conner et al., 2003). Large lesions of the basal forebrain in the rat have resulted in deep coma consistent with the disruption of behavioral output (Fuller et al., 2011). Acetylcholinesterase staining typically stains layer 1 of most cortices, therefore the BF projection appears to primarily target layer 1 of most of the cortex (Bigl et al., 1982). In monkey and human cortex, C3b and C5p neurons appear to preferentially stain for acetylcholinesterase suggesting a prominent utilization of acetylcholine (Bravo and Karten, 1992; Voytko et al., 1992; Hackett et al., 2001).

Viewpoint: Neuroanatomically, the basal forebrain appears to provide cholinergic input to the cerebral cortex to learn and activate an output behavior mapping between $\mathrm{C} 3 \mathrm{~b}$ and $\mathrm{C} 5 \mathrm{p}$ neurons.

\subsubsection{Perspective on behavioral memory output}

Within a homotypical cognitive architecture, if C5p neurons are a form of behavioral output in motor cortex they are a form of behavioral output in the rest of the isocortex. Similarly, if spinocerebellar signals communicate body movement/posture information states to the cerebellum, then $\mathrm{C} 5 \mathrm{p}$ projections to the cerebellum through the pons may communicate analogous cognitive information states from brain (Doya, 1999). Combining the two analogies we hypothesize the $\mathrm{C} 5 \mathrm{p}$ group provides a behavioral output predicting desired future coordinated behaviors. Motor cortex would communicate physical behaviors for the nervous system to operate on, while other isocortical regions would communicate cognitive or perceptual behaviors to various subcortical structures.

The neuroanatomical evidence suggests that acetylcholine delivered by the basal forebrain is critical for the activation and learning of a mapping between $\mathrm{C} 3 \mathrm{~b}$ and $\mathrm{C} 5 \mathrm{p}$ neurons, and that this mapping is the source of cortically learned behavior output and/or skill learning. The relationship of C5p neurons to C3b populations is significant because the C3b population appears to be centrally located in nearly all circuits. Therefore a direct mapping, driven by acetylcholine projections, from stable $\mathrm{C} 3 \mathrm{~b}$ perceptions to C5p behavior output can be developed over time exclusively in the cerebral cortex.

\subsection{COGNITIVE CONTROL: LAYER 1 THALAMOCORTICAL PROJECTION CIRCUIT}

Nervous systems evolved to control muscles through structures like the basal ganglia and cerebellum (Striedter, 2005). Muscles are widely distributed throughout the body, but must be controlled in a coordinated manner. Human cognition, evolving from the same circuitry, is certainly controlled too. However, the neuroanatomical mechanism underlying cognitive control is still an open question.

Along with the basal ganglia, the cerebellum is another structure critical for smooth control of movement and cognition (Ramnani, 
2006). Lesions to the cerebellum often produce dysmetria (lack of coordination of movement) and cerebellar cognitive dysfunction has been described as "dysmetria of thought" (Wolf et al., 2009). By psychological analogy movement and cognition appear to be functionally controlled in the same way.

\subsubsection{Cortical layer $1-L 1$}

Layer 1 of the cerebral cortex, referred to as the molecular layer, lies closest to the pial surface of the brain. The only neurons in L1 are inhibitory Cajal-Retzius cells containing long horizontal axons (Conde et al., 1994; Gabbott and Bacon, 1996; Cajal, 2002). L1 is composed of a dense plexus of dendritic tufts of pyramidal neurons combined with axons from cortical and subcortical origin. Many non-glutamate neurotransmitters systems (serotoninergic, adrenergic, cholinergic) appear to target the lower portions of layer 1 (Eickhoff et al., 2007). The dense plexus of dendrites in L1 provides the opportunity for a given axon terminating in L1 to effect pyramidal neurons throughout all layers. The cortical pyramidal neurons consistently demonstrating prominent L1 apical dendritic tufts are C2, C3a, C3b, C5s, and C5p.

Viewpoint: Neuroanatomically, cortical layer 1 appears to be a plexus of dendrites and axons where a single-axon projection can easily influence or activate multiple pyramidal neurons in different cortical layers to control a functional module.

\subsubsection{Thalamocortical layer 1 projections - TL1}

Herkenham first described a localized region of the thalamus in the mouse, VM, that projected diffusely to layer 1 of nearly the entire cerebral cortex (Herkenham, 1979, 1980). The projection has a decreasing density gradient from frontal cortex (cognitive) to parietal cortex (sensory). Other studies in the rat definitively confirm the VM $\rightarrow$ L1 projection (Arbuthnott et al., 1990; Mitchell and Cauller, 2001). The ventral thalamus in the monkey has significant projections to layer 1 (Nakano et al., 1992; McFarland and Haber, 2002). However, a localized thalamic L1 projection nuclei has not been directly looked for in primates and we use the nuclei VAmc/VM to estimate the localized thalamic TL1 projection source occurring near the mammillothalamic tract that presumably exists in the primate (human). The VAmc/VM nuclei receive projections from the Gpi/Snr and the cerebellum (Sidibe et al., 1997; Parent et al., 2001; Francois et al., 2002) and send projections back to the striatum (McFarland and Haber, 2001). As part of the reticular activating system the ventral (and other thalamic nuclei) receive afferent cholinergic projections from the brainstem (Steriade et al., 1988). We include in the TL1 definition the more sparsely distributed layer 1 projecting thalamic matrix described by Jones (1998).

Historical Note: One of the most perplexing thalamic projections has been the non-specific thalamocortical layer 1 projection described by Lorente de No in the 1940s (Lorente de No, 1943). The intralaminar thalamic nuclei have long been thought to supply the layer 1 projection, but given the infragranular (L5/6) targets of Ti that appears unlikely today (Parent and Parent, 2005). Ironically, the discovery of the actual source of these layer 1 projections was surely, albeit unknowingly, discovered in the early electrophysiology intralaminar recruiting response experiments in cats (Hanbery and Jasper, 1953). Hanbery and Jaspers "discovered $a$ portion of the diffuse projection system which behaves quite differently from [the traditional recruiting response]. In...VA...we have obtained diffuse short latency cortical responses in response to a single shock. . We seem to be stimulating here. . a short latency diffuse projection system, which actually does not give true recruiting responses of the type presumably characteristic of the intralaminar system" (Hanbery and Jasper, 1953). A focused experiment to directly test for this projection in the primate would be fruitful for neuroscience.

Viewpoint: Neuroanatomically, the layer 1 thalamic projection appears to provide short latency cortical stimulation across widespread areas to activate and control cortical information processing.

\subsubsection{Metencephalon - pons, cerebellum}

The metencephalon primarily includes the pons, cerebellum, and deep cerebellar nuclei. The pons receives nearly all its afferent projections from the isocortex and sends nearly all its efferent output to the cerebellum (Brodal and Bjaalie, 1992). This close relationship is demonstrated by the tight correlated volumetric evolution between the pons and cerebral cortex across species. The pons accounting for $6 \%$ of the brainstem in prosimians, $11-21 \%$ in monkeys and $37 \%$ in humans (Brodal and Bjaalie, 1992). As discussed, the pons receives its cortical projection from the C5p cells from nearly the entire cerebral cortex (Brodal, 1978; Leichnetz et al., 1984; Glickstein et al., 1985). A few prefrontal and temporal cortical regions in the primate do not appear to project to the pons (Schmahmann and Pandya, 1995). The pons then continues to project topographically onto the cerebellum (Kelly and Strick, 2003). The output of the cerebellum arises from inhibitory Purkinje cells that target the deep cerebellar nuclei (DCN; Ramnani, 2006). Therefore, like the basal ganglia, the cerebellum functions on the principle of disinhibition. A detailed cerebellum review is useful for understanding the internal cerebellar circuitry (Voogd, 2003). The output of the DCN is an excitatory glutamatergic projection targeting predominantly the ventral thalamus (Sakai et al., 1996). The cortico-cerebellar-thalamocortical circuit results in closed loop topographic projections to wide areas of the frontal, temporal, and parietal cortices (LeVay and Sherk, 1981; Kelly and Strick, 2003).

Viewpoint: Neuroanatomically, the pons integrates and transmits cortically evoked C5p output to the cerebellum. The cerebellum appears to be a control system for fine tuning and stabilizing sequences of movement and cognitive behaviors through the ventral thalamus.

\subsubsection{Perspective on cognitive control}

We present the hypothesis that cognition is fundamentally controlled via the TL1 thalamocortical projection system. We hypothesize all thalamocortical layer 1 projections have a similar functional role in cognitive control through the activation of cortical modules to drive cortico-thalamocortical information processing and working memory. While the VAmc/VM nuclei might be considered "centralized control," the matrix layer 1 projections from other distributed thalamic locations might be considered "local feedback control." 
By analogy, if alpha-motor neurons activate individual muscles and TL1 projections activate individual cortical modules, then the TL1 projecting neurons might be considered "alpha-motor neurons of thought." If a cortical region like Brodmann's area 8 or 9 targets this region with cortico-thalamocortical C6t projections then that region might be considered "primary thought cortex." Human lesion studies to these areas resulting in the elimination of voluntary cognitive processes are consistent with this hypothesis (e.g., patient M.F.; Penfield and Rasmussen, 1968). Multiple experiments could be created to test this hypothesis in the primate, all beginning with first locating the exact thalamic region capable of exciting diffuse surface wave potentials described by Hanbery and Jasper (1953). With the region identified through electrophysiology, behavioral effects of stimulation or lesions can be tested, and the exact afferent/efferent cortical laminar projections can be determined through tracing studies.

\subsection{CORTICAL INFORMATION FLOW REGULATION: CORTICO-CLAUSTRAL-CORTICO CIRCUIT}

The claustrum and related circuitry is one of the least understood functionally. The most prominent ideas implicating the claustrum in the integration of conscious precepts (Crick and Koch, 2005).

\subsubsection{Claustrum - CM}

The claustrum is located midway between layer 6 of insular cortex (from which it breaks off early in brain development) and the striatum. Debate is ongoing on whether the claustrum's developmental origin is cortical, striatal, or a hybrid (Edelstein and Denaro, 2004).

Projections from the claustrum target nearly the entire brain, with little segregation of projections in the claustrum (TanneGariepy et al., 2002). Claustrum projections travel through the external capsule and appear slightly biased to cognitive and cortical control centers of the brain (Molnar et al., 2006). The projections from the claustrum terminate mostly in layer 4 and appear to preferentially target inhibitory neurons, possibly chandelier cells with axoaxonic terminals (LeVay and Sherk, 1981; LeVay, 1986).

Viewpoint: Neuroanatomically, the claustrum appears to integrate cortical information from C6m neurons and provide feedforward excitatory input to inhibitory neurons in L4 of the cerebral cortex.

\subsubsection{Cortical layer 6 claustrum projecting - C6m}

The claustrum receives projections from virtually the entire cortex in a topographic, but largely overlapped fashion (Pearson et al., 1982). The projections from cortex originate from C6m neurons, which are distinct from C6t neurons in the cat (Katz, 1987). Apical dendrites of these neurons typically arborize directly below layer 4 in the upper part of layer 5 (Lorente de No, 1943; Soloway et al., 2002). Occasionally collaterals of C5s neurons are found in the claustrum (Parent and Parent, 2006).

Viewpoint: Neuroanatomically, C6m appears to function in coordination with $\mathrm{C} 5 \mathrm{~s}$ neurons to integrate action suggestions for transmission to the claustrum.

\subsubsection{Perspective on the claustrum}

The claustrum's functional connections are suited to regulate the flow of information between wide areas of the cortex, potentially through the excitation of inhibitory chandelier type cells. Activation of inhibitory chandelier cells would immediately prevent the transmission of action potentials from active neurons in layers 3-5 without reducing the excitation of the neuron. Notable is the C6m dendritic and axon projections to layer 5a containing C5s striatally projecting cells. The additional relationship of the claustrum to striatally projecting neurons further implies, through analogous function, selection and/or gating of information.

\section{SUMMARY PERSPECTIVE ON NEUROANATOMICAL INFORMATION FLOW}

Figure 5 shows the hypothesized organization of seven circuits viewable from two perspectives: circuit development and information flow. As a summary, we hypothesize a simplified but comprehensive cognitive framework mutually consistent with the summarized neuroanatomical facts. Rather than being exhaustive, Figure 5 and each outline attempt to deliver the gist of information flow as a conceptual framework. All colors correspond to Figure 5. Each hypothesis is best viewed as a focused question of interest within the field of neuroanatomy and suitable for the topic of a graduate student's dissertation.

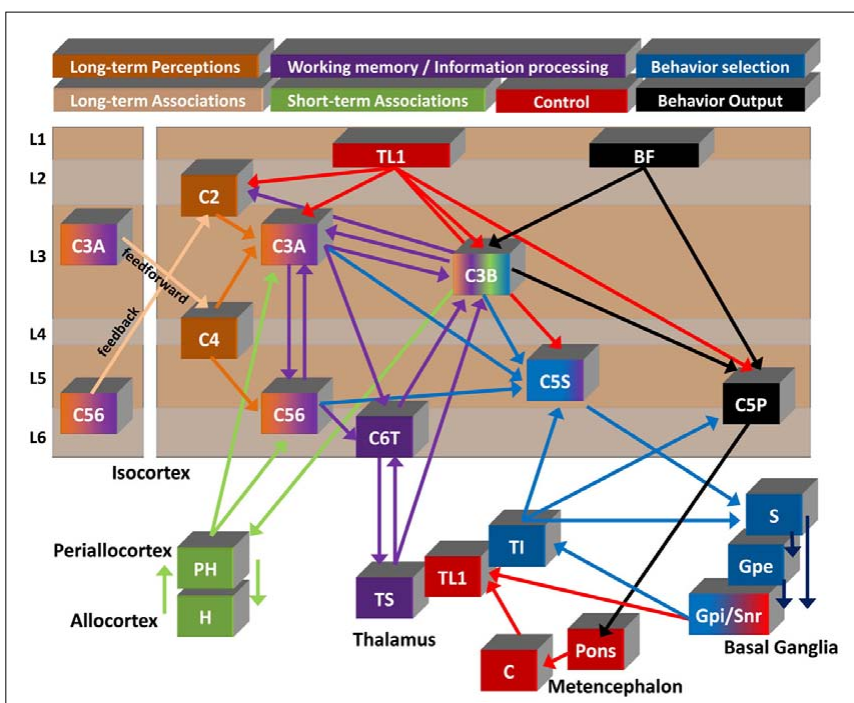

FIGURE 5 | Summary diagram of proposed flow of cognitive information. Seven of the circuits described in the text are shown to illustrate a summarized functional viewpoint of the hypothesized flow of information. Generally information flows from left to right through the color coded circuits. Circuit names and colors are represented at the top. Long-term memory is split into "perceptions" and "associations" as discussed in 4.1. Information flow details are describe in the text. Cortical neuron $x(\mathrm{Cx})$, Parahippocampal gyrus $(\mathrm{PH})$, Hippocampus $(\mathrm{H})$, Specific thalamus (Ts), Layer 1 projecting thalamus (TL1), Intralaminar thalamus (Ti), Cerebellum (C), Striatum (S), External segment globus pallidus (Gpe), Internal segment globus pallidus (Gpi), Substantia nigra par reticulata (Snr), Basal forebrain (BF; note: the basal forebrain is placed in layer 1 to demonstrate the primary target of its projections). 


\subsection{PERSPECTIVE ON COGNITIVE DEVELOPMENT}

We briefly hypothesize the development of the circuits in the maturing brain in relation to Figure 5.

- Layer 4 feedforward projections drive the formation of perceptual cell assemblies in C3a and C56 (orange).

- Critical periods first regulate the formation of cell assemblies within and between neuronal groups C3a and C56, followed by C3b and C6t (orange/purple).

- Stable invariant $\mathrm{C} 3 \mathrm{~b}$ representations are simultaneously formed through intercortical C4 feedforward and C2 feedback influence and C3a intracortical input (orange/purple/green).

- Stable C3b representations in different cortical modules are associated when temporally coactive in the hippocampus (green).

- During sleep cycles most behavioral selection (blue) and behavior output (black) circuits are shut down and working memory (purple) and short-term memory circuits (green) are active in order to consolidate shortterm memory (green) into intercortical long-term memory (orange).

- Action representations (C5s) form to communicate cortical action behaviors to the basal ganglia (blue). The claustrum may be important in this development.

- Dopamine input to the striatum from the Snc is used to reward or anti-reward C5s action sequence selection, learning combinatorial sequences from the cortical modular hierarchy (blue).

- Ti projects upon the lower layers of the isocortex (C5s blue/C5p black) to aid in the selection of behaviors.

- Successful output behaviors, determined by cholinergic basal forebrain activity, reinforce the mapping between C3b and C5p for direct activation of learned behaviors (black).

- The cerebellum learns to aid in ventral thalamic control (red) in response to C5p cortical output.

\subsection{PERSPECTIVE ON DEVELOPED COGNITIVE INFORMATION PROCESSING}

We briefly hypothesize the utilization of the circuits in the matured brain in relation to Figure 5 .

- Instigation of cognitive information processing begins with the layer 1 control projections (TL1 red) to the cerebral cortex. The cholinergic reticular activating system turns on thalamic nuclei.

- Control inputs drive cortico-thalamocortical information processing (purple) to select active C3b perceptions simultaneously in multiple cortical modules.

- Long-term memory associations (orange) and short-term memory (green) simultaneously bias the selection of $\mathrm{C} 3 \mathrm{~b}$ perceptions in target cortical modules.

- C5s cortical action suggestions are communicated to the basal ganglia for selection (blue).

\section{REFERENCES}

Alexander, G. E., DeLong, M. R., and Strick, P. L. (1986). Parallel organization of functionally segregated circuits linking basal ganglia and cortex. Annu. Rev. Neurosci. 9, 357-381.

Ascoli, G. A., Alonso-Nanclares, L., Anderson, S. A., Barrionuevo, G., Benavides-Piccione, R., Burkhalter,

- $\mathrm{C} 3 \mathrm{~b}$ perceptions trigger output C5p groups (black) that communicate cognitive output to the cerebellum (red) or directly cause physical behavior in motor cortex.

- Cognitive control via TL1 (red) is simultaneously driven by basal ganglia, cerebellar, and direct frontal cortex C6t input, resulting in ongoing "self-controlled thought."

\section{CONCLUDING REMARKS}

The causal function of any brain must ultimately be described in terms of a neuroanatomical description. Neuroanatomy must form the foundation of our understanding of the brain and experimental evidence should be explained in terms of neuroanatomical circuitry. The introduction of new experimental methods and the fragmentation of disciplines has scattered a vast numbers of anatomical puzzle pieces across the neuroscience information landscape. Cognitive consilience is a start to putting the puzzle pieces together. The picture is not perfect, but we have formed the beginning of a complete picture and re-introduced important neuroanatomical information that appears to have been lost in the literature. We have utilized technology to bring neuroanatomy literature and a synthesized picture of neuroanatomical circuits to anyone's fingertips and have put forth several novel and bold testable hypothesis on the neuroanatomical function of the brain.

The field of neuroanatomy is still in its infancy, the modern form beginning just over 100 years ago. Although modern technology has introduced novel experimental methods, huge gaps exist in our neuroanatomical knowledge for unexplained reasons. The last comprehensive Golgi staining assessment of a complete brain was published in 1899-1904 (Cajal, 2002). The last comprehensive histological Nissl staining study of a human brain was published in 1929 (von Economo, 1929). While these works were seminal and have lasted the test of time, the study by von Economo involves roughly 100 photographs of the human brain. Why not advance our understanding by redoing Cajal's seminal work or redoing von Economo's complete brain histology with twenty-first century capabilities?

A wealth of information and knowledge is piling up, while significantly more has been passed over. Consilience will ultimately be needed to arrive at our final understanding of the brain.

\section{ACKNOWLEDGMENTS}

The first author would like to acknowledge the initial support and encouragement of Robert Hecht-Nielsen in establishing the present research. The first author would also like to thank Glenn Northcutt and the late Ted Jones for their discussions, feedback, and encouragement to publish the research. The second author would like to acknowledge support from the UCSD Autism Center of Excellence, National Institutes of Health Grant 1-P50MH081755, and the Simons Foundation for Autism Research Initiative (SFARI). The authors would like to thank SFARI for financial support to publish this work. Soren Solari was responsible for the neuroanatomical research and graphics and Rich Stoner was responsible for the technological integration and visualization.

A., Buzsáki, G., Cauli, B., Defelipe,

J., Fairén, A., Feldmeyer, D., Fishell,

G., Fregnac, Y., Freund, T. F., Gard-

ner, D., Gardner, E. P., Goldberg,

J. H., Helmstaedter, M., Hestrin, S.,
Karube, F., Kisvárday, Z. F., Lambolez, B., Lewis, D. A., Marin, O., Markram, H., Muñoz, A., Packer, A., Petersen, C. C., Rockland, K. S., Rossier, J., Rudy, B., Somogyi, P. 
Staiger, J. F., Tamas, G., Thomson, A. M., Toledo-Rodriguez, M., Wang, Y., West, D. C., and Yuste, R. (2008). Petilla terminology: nomenclature of features of GABAergic interneurons of the cerebral cortex. Nat. Rev. Neurosci. 9, 557-568.

Amaral, D. G., and Cowan, W. M. (1980). Subcortical afferents to the hippocampal formation in the monkey. J. Comp. Neurol. 189, 573-591.

Amaral, D. G., and Witter, M. P. (1989). The three-dimensional organization of the hippocampal formation: a review of anatomical data. Neuroscience 31, 571-591.

Apicella, P. (2007). Leading tonically active neurons of the striatum from reward detection to context recognition. Trends Neurosci. 30, 299-306.

Arbuthnott, G. W., MacLeod, N. K., Maxwell, D. J., and Wright, A. K. (1990). Distribution and synaptic contacts of the cortical terminals arising from neurons in the rat ventromedial thalamic nucleus. Neuroscience $38,47-60$.

Arikuni, T., and Kubota, K. (1986). The organization of prefrontocaudate projections and their laminar origin in the macaque monkey: a retrograde study using hrp-gel. J. Comp. Neurol. 244, 492-510.

Asanuma, C. (1994). Gabaergic and pallidal terminals in the thalamic reticular nucleus of squirrel monkeys. Exp. Brain Res. 101, 439-451.

Asanuma, C., Andersen, R. A., and Cowan, W. M. (1985). The thalamic relations of the caudal inferior parietal lobule and the lateral prefrontal cortex in monkeys: divergent cortical projections from cell clusters in the medial pulvinar nucleus. J. Comp. Neurol. 241, 357-381.

Baddeley, A. (1981). The concept of working memory: a view of its current state and probable future development. Cognition 10, 17-23.

Baleydier, C., and Mauguiere, F. (1987). Network organization of the connectivity between parietal area 7 , posterior cingulate cortex and medial pulvinar nucleus: a double fluorescent tracer study in monkey. Exp. Brain Res. 66, 385-393.

Barbas, H. (1986). Pattern in the laminar origin of corticocortical connections. J. Comp. Neurol. 252, 415-422.

Barbas, H., Hilgetag, C. C., Saha, S., Dermon, C. R., and Suski, J. L. (2005a). Parallel organization of contralateral and ipsilateral prefrontal cortical projections in the rhesus monkey. BMCNeurosci. 6, 32 . doi:10.1186/1471-2202-6-32
Barbas, H., Medalla, M., Alade, O., Suski, J., Zikopoulos, B., and Lera, P. (2005b). Relationship of prefrontal connections to inhibitory systems in superior temporal areas in the rhesus monkey. Cereb. Cortex 15, 1356-1370.

Barbas, H., and Rempel-Clower, N. (1997). Cortical structure predicts the pattern of corticocortical connections. Cereb. Cortex 7, 635-646.

Benke, T., Delazer, M., Bartha, L., and Auer, A. (2003). Basal ganglia lesions and the theory of fronto-subcortical loops: neuropsychological findings in two patients with left caudate lesions. Neurocase 9, 70-85.

Bigl, V., Woolf, N. J., and Butcher, L. L. (1982). Cholinergic projections from the basal forebrain to frontal, parietal, temporal, occipital, and cingulate cortices: a combined fluorescent tracer and acetylcholinesterase analysis. Brain Res. Bull. 8, 727-749.

Borgmann, S., and Jurgens, U. (1999). Lack of cortico-striatal projections from the primary auditory cortex in the squirrel monkey. Brain Res. 836, 225-228.

Bottjer, S. W. (2005). Timing and prediction the code from basal ganglia to thalamus. Neuron 46, 4-7.

Braak, H., and Braak, E. (1976). The pyramidal cells of betz within the cingulate and precentral gigantopyramidal field in the human brain. A Golgi and pigmentarchitectonic study. Cell Tissue Res. 172, 103-119.

Bravo, H., and Karten, H. J. (1992). Pyramidal neurons of the rat cerebral cortex, immunoreactive to nicotinic acetylcholine receptors, project mainly to subcortical targets. $J$. Comp. Neurol. 320, 62-68.

Briggs, F., and Callaway, E. M. (2001). Layer-specific input to distinct cell types in layer 6 of monkey primary visual cortex. J. Neurosci. 21, 3600-3608.

Briggs, F., and Callaway, E. M. (2005). Laminar patterns of local excitatory input to layer 5 neurons in macaque primary visual cortex. Cereb. Cortex $15,479-488$.

Brodal, P. (1978). The corticopontine projection in the rhesus monkey. Origin and principles of organization. Brain 101, 251-283.

Brodal, P., and Bjaalie, J. G. (1992). Organization of the pontine nuclei. Neurosci. Res. 13, 83-118.

Brodmann, K. (1909). Brodmann's "Localisation in the Cerebral Cortex." London: Smith-Gordon.

Bromberg-Martin, E. S., Matsumoto, M., and Hikosaka, O. (2010). Dopamine in motivational control: rewarding, aversive, and alerting. Neuron 68, 815-834.
Brunel, N., and Wang, X. J. (2001). Effects of neuromodulation in a cortical network model of object working memory dominated by recurrent inhibition. J. Comput. Neurosci. 11, 63-85.

Brysch, I., Brysch, W., Creutzfeldt, O., Hayes, N. L., and Schlingensiepen, K. H. (1984). The second, intralaminar thalamo-cortical projection system. Anat. Embryol. 169, 111-118.

Brysch, W., Brysch, I., Creutzfeldt, O. D., Schlingensiepen, R., and Schlingensiepen, K. H. (1990). The topology of the thalamo-cortical projections in the marmoset monkey (Callithrix jacchus). Exp. Brain Res. 81, 1-17.

Burwell, R. D. (2000). The parahippocampal region: corticocortico connectivity. Ann. N. Y. Acad. Sci. 911, 25-42.

Buxhoeveden, D. P., and Casanova, M. F. (2002). The minicolumn hypothesis in neuroscience. Brain 125, 935-951.

Buzsaki, G. (2006). Rhythms of the Brain. New york: Oxford University Press.

Cajal, S. R. y. (1899). Textura del sistema nervioso del hombre y de los vertebrados, Vol. 1. Madrid: Imprenta y Librera de Nicols Moya.

Cajal, S. R. y. (2002). Texture of the Nervous System of Man and the Vertebrates, Vol. 3. New York: SpringerVerlag.

Callaway, E. M. (1998). Local circuits in primary visual cortex of the macaque monkey. Annu. Rev. Neurosci. $21,47-74$.

Canolty, R. T., Edwards, E., Dalal, S. S. Soltani, M., Nagarajan, S. S., Kirsch, H. E., Berger, M. S., Barbaro, N. M., and Knight, R. T. (2006). High gamma power is phase-locked to theta oscillations in human neocortex. Science 313, 1626-1628.

Catani, M., and ffytche, D. H. (2005). The rises and falls of disconnection syndromes. Brain 128, 2224-2239.

Catsman-Berrevoets, C. E., and Kuypers, H. G. (1978). Differential laminar distribution of corticothalamic neurons projecting to the $\mathrm{vl}$ and the center median. An hrp study in the cynomolgus monkey. Brain Res. 154, 359-365.

Charara, A., and Parent, A. (1994) Brainstem dopaminergic, cholinergic and serotoninergic afferents to the pallidum in the squirrel monkey. Brain Res. 640, 155-170.

Compte, A., Brunel, N., GoldmanRakic, P. S., and Wang, X. J. (2000). Synaptic mechanisms and network dynamics underlying spatial working memory in a cortical network model. Cereb. Cortex 10, 910-923.

Conde, F., Lund, J. S., Jacobowitz, D. M., Baimbridge, K. G., and Lewis,
D. A. (1994). Local circuit neurons immunoreactive for calretinin, calbindin $\mathrm{d}-28 \mathrm{k}$ or parvalbumin in monkey prefrontal cortex: distribution and morphology. J. Comp. Neurol. 341, 95-116.

Conner, J. M., Culberson, A., Packowski, C., Chiba, A. A., and Tuszynski, M. H. (2003). Lesions of the basal forebrain cholinergic system impair task acquisition and abolish cortical plasticity associated with motor skill learning. Neuron 38 , 819-829.

Crick, F. C., and Koch, C. (2005). What is the function of the claustrum? Philos. Trans. R. Soc. Lond. B Biol. Sci. 360, 1271-1279.

Damasio, H., and Damasio, A. R. (1980). The anatomical basis of conduction aphasia. Brain 103, 337-350.

de Lima, A. D., Voigt, T., and Morrison, J. H. (1990). Morphology of the cells within the inferior temporal gyrus that project to the prefrontal cortex in the macaque monkey. J. Comp. Neurol. 296, 159-172.

DeFelipe, J. (1997). Types of neurons, synaptic connections and chemical characteristics of cells immunoreactive for calbindin-d28k, parvalbu$\mathrm{min}$ and calretinin in the neocortex. J. Chem. Neuroanat. 14, 1-19.

DeFelipe, J., Conley, M., and Jones, E. G. (1986). Long-range focal collateralization of axons arising from corticocortical cells in monkey sensory-motor cortex. J. Neurosci. 6 , 3749-3766.

Defelipe, J., Gonzalez-Albo, M. C., Del Rio, M. R., and Elston, G. N. (1999). Distribution and patterns of connectivity of interneurons containing calbindin, calretinin, and parvalbumin in visual areas of the occipital and temporal lobes of the macaque monkey. J. Comp. Neurol. 412, 515-526.

Doya, K. (1999). What are the computations of the cerebellum, the basal ganglia and the cerebral cortex? Neural Netw. 12, 961-974.

Durstewitz, D., Seamans, J. K., and Sejnowski, T. J. (2000). Neurocomputational models of working memory. Nat. Neurosci. 3(Suppl.), 1184-1191.

Edelstein, L. R., and Denaro, F. J. (2004). The claustrum: a historical review of its anatomy, physiology, cytochemistry and functional significance. Cell. Mol. Biol. 50, 675-702.

Edwards, E., Soltani, M., Deouell, L. Y., Berger, M. S., and Knight, R. T. (2005). High gamma activity in response to deviant auditory stimuli recorded directly from human cortex. J. Neurophysiol. 94, 4269-4280. 
Eichenbaum, H. (2000). A corticalhippocampal system for declarative memory. Nat. Rev. Neurosci. 1, 41-50.

Eickhoff, S. B., Schleicher, A., Scheperjans, F., Palomero-Gallagher, N., and Zilles, K. (2007). Analysis of neurotransmitter receptor distribution patterns in the cerebral cortex. Neuroimage 34, 1317-1330.

Felleman, D. J., and Van Essen, D. C. (1991). Distributed hierarchical processing in the primate cerebral cortex. Cereb. Cortex 1, 1-47.

Foster, R. E., Donoghue, J. P., and Ebner, F. F. (1981). Laminar organization of efferent cells in the parietal cortex of the virginia opossum. Exp. Brain Res. 43, 330-336.

Francois, C., Tande, D., Yelnik, J., and Hirsch, E. C. (2002). Distribution and morphology of nigral axons projecting to the thalamus in primates. J. Comp. Neurol. 447, 249-260.

Fujita, I., and Fujita, T. (1996). Intrinsic connections in the macaque inferior temporal cortex. J. Comp. Neurol. 368, 467-486.

Fujiyama, F., Sohn, J., Nakano, T., Furuta, T., Nakamura, K. C., Matsuda, W., and Kaneko, T. (2011). Exclusive and common targets of neostriatofugal projections of rat striosome neurons: a single neurontracing study using a viral vector. Eur. J. Neurosci. 33, 668-677.

Fuller, P., Sherman, D., Pedersen, N. P., Saper, C. B., and Lu, J. (2011). Reassessment of the structural basis of the ascending arousal system. J. Comp. Neurol. 519, 933-956.

Fuster, J. M. (2003). Cortex and Mind. New York: Oxford University Press.

Gabbott, P. L., and Bacon, S. J. (1996). Local circuit neurons in the medial prefrontal cortex (areas 24a,b,c, 25 and 32) in the monkey: I. Cell morphology and morphometrics. J. Comp. Neurol. 364, 567-608.

Gandia, J. A., De Las Heras, S., Garcia, M., and Gimenez-Amaya, J. M. (1993). Afferent projections to the reticular thalamic nucleus from the globus pallidus and the substantia nigra in the rat. Brain Res. Bull. 32, 351-358.

Gerfen, C. R. (1984). The neostriatal mosaic: compartmentalization of corticostriatal input and striatonigral output systems. Nature 311, 461-464.

Gerfen, C. R. (1989). The neostriatal mosaic: striatal patch-matrix organization is related to cortical lamination. Science 246, 385-388.

Gerfen, C. R., and Surmeier, D. J. (2010). Modulation of striatal projection systems by dopamine. Annu. Rev. Neurosci. 34, 441-466.

Geschwind, N. (1965a). Disconnexion syndromes in animals and man. i. Brain 88, 237-294.

Geschwind, N. (1965b). Disconnexion syndromes in animals and man. ii. Brain 88, 585-644.

Ghosh, S., and Porter, R. (1988). Morphology of pyramidal neurones in monkey motor cortex and the synaptic actions of their intracortical axon collaterals. J. Physiol. (Lond.) 400, 593-615.

Gibson, J. R., Beierlein, M., and Connors, B. W. (1999). Two networks of electrically coupled inhibitory neurons in neocortex. Nature 402, 75-79.

Giguere, M., and Goldman-Rakic, P. S (1988). Mediodorsal nucleus: areal, laminar, and tangential distribution of afferents and efferents in the frontal lobe of rhesus monkeys. $J$. Comp. Neurol. 277, 195-213.

Glickstein, M., May, J. G., and Mercier, B. E. (1985). Corticopontine projection in the macaque: the distribution of labelled cortical cells after large injections of horseradish peroxidase in the pontine nuclei. $J$. Comp. Neurol. 235, 343-359.

Goldman-Rakic, P. S. (1996). Regional and cellular fractionation of working memory. Proc. Natl. Acad. Sci. U.S.A. 93, 13473-13480.

Goldman-Rakic, P. S., and Porrino, L. J. (1985). The primate mediodorsal (md) nucleus and its projection to the frontal lobe. J. Comp. Neurol. 242, 535-560.

Gould, E. (2007). How widespread is adult neurogenesis in mammals? Nat. Rev. Neurosci. 8, 481-488.

Grafton, S. T., Arbib, M. A., Fadiga, L., and Rizzolatti, G. (1996). Localization of grasp representations in humans by positron emission tomography. Exp. Brain Res. 112, 103-111.

Graham, R. C. Jr., and Karnovsky, M. J. (1966). The early stages of absorption of injected horseradish peroxidase in the proximal tubules of mouse kidney: ultrastructural cytochemistry by a new technique. J. Histochem. Cytochem. 14, 291-302.

Grenier, F., Timofeev, I., and Steriade, M. (1998). Leading role of thalamic over cortical neurons during postinhibitory rebound excitation. Proc. Natl. Acad. Sci. U.S.A. 95, 13929-13934.

Haber, S. N. (2003). The primate basal ganglia: parallel and integrative networks. J. Chem. Neuroanat. 26, 317-330.
Haber, S. N., Lynd, E., Klein, C., and Groenewegen, H. J. (1990). Topographic organization of the ventral striatal efferent projections in the rhesus monkey: an anterograde tracing study. J. Comp. Neurol. 293, 282-298.

Hackett, T. A., Preuss, T. M., and Kaas, J. H. (2001). Architectonic identification of the core region in auditory cortex of macaques, chimpanzees, and humans. J. Comp. Neurol. 441, 197-222.

Hagmann, P., Cammoun, L., Gigandet, X., Gerhard, S., Grant, P. E., Wedeen, V., Meuli, R., Thiran, J. P., Honey, C. J., and Sporns, O. (2010). Mr connectomics: principles and challenges. J. Neurosci. Methods 194, 34-45.

Hamani, C., Dostrovsky, J. O., and Lozano, A. M. (2006). The motor thalamus in neurosurgery. Neurosurgery 58, 146-58; discussion 146-158.

Hanbery, J., and Jasper, H. (1953). Independence of diffuse thalamocortical projection system shown by specific nuclear destructions. J. Neurophysiol. 16, 252-271.

Hanbery, J., and Jasper, H. (1954). The non-specific thalamocortical projection system. J. Neurosurg. 11, 24-25.

Hardman, C. D., Henderson, J. M. Finkelstein, D. I., Horne, M. K., Paxinos, G., and Halliday, G. M. (2002). Comparison of the basal ganglia in rats, marmosets, macaques, baboons, and humans: volume and neuronal number for the output, internal relay, and striatal modulating nuclei. J. Comp. Neurol. 445, 238-255.

Hazrati, L. N., and Parent, A. (1991a). Contralateral pallidothalamic and pallidotegmental projections in primates: an anterograde and retrograde labeling study. Brain Res. 567, 212-223.

Hazrati, L. N., and Parent, A. (1991b). Projection from the external pallidum to the reticular thalamic nucleus in the squirrel monkey. Brain Res. 550, 142-146.

Hebb, D. O. (1949). The Organization of Behavior: A Neuropsychological Theory. New York: Lawrence Erlbaum Associates.

Heindel, W., Salmon, D., Shults, C., Walicke, P., and Butters, N. (1989). Neuropsychological evidence for multiple implicit memory systems: a comparison of Alzheimer's, Huntington's, and Parkinson's disease patients. J. Neurosci. 9, 582-587.

Herkenham, M. (1979). The afferent and efferent connections of the ventromedial thalamic nucleus in the rat. J. Comp. Neurol. 183, 487-517.

Herkenham, M. (1980). Laminar organization of thalamic projections to the rat neocortex. Science 207, 532-535.

Herrero, M. T., Barcia, C., and Navarro, J. M. (2002). Functional anatomy of thalamus and basal ganglia. Childs Nerv. Syst. 18, 386-404.

Hestrin, S., and Galarreta, M. (2005). Electrical synapses define networks of neocortical gabaergic neurons. Trends Neurosci. 28, 304-309.

Hohl-Abrahao, J. C., and Creutzfeldt, O. D. (1991). Topographical mapping of the thalamocortical projections in rodents and comparison with that in primates. Exp. Brain Res. 87, 283-294.

Insausti, R., Amaral, D. G., and Cowan, W. M. (1987). The entorhinal cortex of the monkey: Iii. Subcortical afferents. J. Comp. Neurol. 264, 396-408.

Jones, E. G. (1975). Some aspects of the organization of the thalamic reticular complex. J. Comp. Neurol. 162, 285-308.

Jones, E. G. (1998). Viewpoint: the core and matrix of thalamic organization. Neuroscience 85, 331-345.

Jones, E. G. (2007). The Thalamus, 2nd Edn, Vol. 1-2. Cambridge: Cambridge University Press.

Jones, E. G., and Burton, H. (1976) Areal differences in the laminar distribution of thalamic afferents in cortical fields of the insular, parietal and temporal regions of primates. $J$. Comp. Neurol. 168, 197-247.

Jones, E. G., Coulter, J. D., Burton, H., and Porter, R. (1977). Cells of origin and terminal distribution of corticostriatal fibers arising in the sensory-motor cortex of monkeys. J. Comp. Neurol. 173, 53-80.

Jones, E. G., and Wise, S. P. (1977). Size, laminar and columnar distribution of efferent cells in the sensory-motor cortex of monkeys. J. Comp. Neurol. 175, 391-438.

Kakei, S., Na, J., and Shinoda, Y. (2001). Thalamic terminal morphology and distribution of single corticothalamic axons originating from layers 5 and 6 of the cat motor cortex. J. Comp. Neurol. 437, 170-185.

Kaneko, T., Cho, R., Li, Y., Nomura, S., and Mizuno, N. (2000). Predominant information transfer from layer iii pyramidal neurons to corticospinal neurons. J. Comp. Neurol. 423, 52-65.

Katz, L. C. (1987). Local circuitry of identified projection neurons in cat visual cortex brain slices. J. Neurosci. 7, 1223-1249. 
Kawaguchi, Y., Wilson, C. J., Augood, S. J., and Emson, P. C. (1995). Striatal interneurones: chemical, physiological and morphological characterization. Trends Neurosci. 18, 527-535.

Kelly, R. M., and Strick, P. L. (2003). Cerebellar loops with motor cortex and prefrontal cortex of a nonhuman primate. J. Neurosci. 23, 8432-8444.

Kievit, J., and Kuypers, H. G. (1977). Organization of the thalamocortical connexions to the frontal lobe in the rhesus monkey. Exp. Brain Res. 29, 299-322.

Kimura, F., and Itami, C. (2009). Myelination and isochronicity in neural networks. Front. Neuroanat. 3:12. doi:10.3389/neuro.05.012.2009

Kimura, T., Ozaki, I., and Hashimoto, I. (2008). Impulse propagation along thalamocortical fibers can be detected magnetically outside the human brain. J. Neurosci. 28, 12535-12538.

Knight, R. T. (2007). Neuroscience. Neural networks debunk phrenology. Science 316, 1578-1579.

Kobayashi, Y., and Amaral, D. G. (2003). Macaque monkey retrosplenial cortex: Ii. Cortical afferents. J. Comp. Neurol. 466, 48-79.

Kobayashi, Y., and Amaral, D. G. (2007). Macaque monkey retrosplenial cortex: Iii. Cortical efferents. J. Comp. Neurol. 502, 810-833.

Kotter, R. (2004). Online retrieval, processing, and visualization of primate connectivity data from the cocomac database. Neuroinformatics 2, 127-144.

Kreczmanski, P., Heinsen, H., Mantua, V., Woltersdorf, F., Masson, T., Ulfig, N., Schmidt-Kastner, R., Korr, H., Steinbusch, H. W., Hof, P. R., and Schmitz, C. (2007). Volume, neuron density and total neuron number in five subcortical regions in schizophrenia. Brain 130(Pt 3):678-692.

Kristensson, K., and Olsson, Y. (1971). Retrograde axonal transport of protein. Brain Res. 29, 363-365.

Kritzer, M. F., and Goldman-Rakic, P. S. (1995). Intrinsic circuit organization of the major layers and sublayers of the dorsolateral prefrontal cortex in the rhesus monkey. J. Comp. Neurol. 359, 131-143.

Kunishio, K., and Haber, S. N. (1994). Primate cingulostriatal projection: limbic striatal versus sensorimotor striatal input. J. Comp. Neurol. 350 , 337-356.

Langer, L. F., and Graybiel, A. M. (1989). Distinct nigrostriatal projection systems innervate striosomes and matrix in the primate striatum. Brain Res. 498, 344-350.
Lauterbach, E. C. (2005). The neuropsychiatry of Parkinson's disease. Minerva Med. 96, 155-173.

Lavenex, P., Suzuki, W. A., and Amaral, D. G. (2002). Perirhinal and parahippocampal cortices of the macaque monkey: projections to the neocortex. J. Comp. Neurol. 447, 394-420.

Lee, C. R., and Tepper, J. M. (2009). Basal ganglia control of substantia nigra dopaminergic neurons. $J$. Neural Transm. Suppl. 73, 71-90.

Leichnetz, G. R., Smith, D. J., and Spencer, R. F. (1984). Cortical projections to the paramedian tegmental and basilar pons in the monkey. J. Comp. Neurol. 228, 388-408.

Lemon, R. N., and Griffiths, J. (2005). Comparing the function of the corticospinal system in different species: organizational differences for motor specialization? Muscle Nerve 32, 261-279.

Letinic, K., Zoncu, R., and Rakic, P. (2002). Origin of gabaergic neurons in the human neocortex. Nature 417, 645-649.

LeVay, S. (1986). Synaptic organization of claustral and geniculate afferents to the visual cortex of the cat. J. Neurosci. 6, 3564-3575

LeVay, S., and Sherk, H. (1981). The visual claustrum of the cat. i. Structure and connections. J. Neurosci. 1, 956-980.

Levesque, J. C., and Parent, A. (2005a). Gabaergic interneurons in human subthalamic nucleus. Mov. Disord. 20, 574-584.

Levesque, M., and Parent, A. (2005b). The striatofugal fiber system in primates: a reevaluation of its organization based on single-axon tracing studies. Proc. Natl. Acad. Sci. U.S.A. 102, 11888-11893.

Levesque, M., Gagnon, S., Parent, A., and Deschenes, M. (1996). Axonal arborizations of corticostriatal and corticothalamic fibers arising from the second somatosensory area in the rat. Cereb. Cortex 6, 759-770.

Levitt, J. B., Lewis, D. A., Yoshioka, T., and Lund, J. S. (1993). Topography of pyramidal neuron intrinsic connections in macaque monkey prefrontal cortex (areas 9 and 46). J. Comp. Neurol. 338, 360-376.

Lieber, R. L. (2002). Skeletal Muscle Structure, Function, and Plasticity, 2nd Edn. Philadelphia: Lippincott Williams and Wilkins.

Lorente de No, R. (1943). "Cerebral cortex: architecture, intracortical connections, motor projections," in Physiology of the Nervous System,
Outlines of Physiology Series, 2nd Edn, ed. J. Fulton (New York: Oxford University Press), 274-301.

Lund, J. S., Hendrickson, A. E., Ogren, M. P., and Tobin, E. A. (1981) Anatomical organization of primate visual cortex area vii. J. Comp. Neurol. 202, 19-45.

Lund, J. S., and Lewis, D. A. (1993). Local circuit neurons of developing and mature macaque prefrontal cortex: Golgi and immunocytochemical characteristics. J. Comp. Neurol. 328 282-312.

Lund, J. S., Yoshioka, T., and Levitt, J. B. (1993). Comparison of intrinsic connectivity in different areas of macaque monkey cerebral cortex. Cereb. Cortex 3, 148-162.

Macchi, G., and Jones, E. G. (1997). Toward an agreement on terminology of nuclear and subnuclear divisions of the motor thalamus. J. Neurosurg. 86, 670-685.

Marcus, D. S., Harwell, J., Olsen, T. Hodge, M., Glasser, M. F., Prior, F., Jenkinson, M., Laumann, T., Curtiss, S. W., and Van Essen, D. C. (2011). Informatics and data mining tools and strategies for the human connectome project. Front. Neuroinform. 5:4 doi:10.3389/fninf.2011.00004

Matsuda, W., Furuta, T., Nakamura, K. C., Hioki, H., Fujiyama, F., Arai, R., and Kaneko, T. (2009). Single nigrostriatal dopaminergic neurons form widely spread and highly dense axonal arborizations in the neostriatum. J. Neurosci. 29, 444-453.

McFarland, N. R., and Haber, S. N. (2001). Organization of thalamostriatal terminals from the ventral motor nuclei in the macaque. $J$. Comp. Neurol. 429, 321-336.

McFarland, N. R., and Haber, S. N. (2002). Thalamic relay nuclei of the basal ganglia form both reciprocal and nonreciprocal cortical connections, linking multiple frontal cortical areas. J. Neurosci. 22, 8117-8132.

Medalla, M., and Barbas, H. (2006). Diversity of laminar connections linking periarcuate and lateral intraparietal areas depends on cortical structure. Eur. J. Neurosci. 23 , 161-179.

Melchitzky, D. S., Gonzalez-Burgos, G., Barrionuevo, G., and Lewis, D. A. (2001). Synaptic targets of the intrinsic axon collaterals of supragranular pyramidal neurons in monkey prefrontal cortex. J. Comp. Neurol. 430, 209-221.

Meyer, G., Gonzalez-Hernandez, T. H. and Ferres-Torres, R. (1989). The spiny stellate neurons in layer iv of the human auditory cortex. A Golgi study. Neuroscience 33, 489-498.

Milner, B. (2005). The medial temporallobe amnesic syndrome. Psychiatr. Clin. North Am. 28, 599-611.

Mitchell, B. D., and Cauller, L. J. (2001). Corticocortical and thalamocortical projections to layer $\mathrm{i}$ of the frontal neocortex in rats. Brain Res. 921, 68-77.

Molnar, Z., and Cheung, A. F. (2006) Towards the classification of subpopulations of layer $\mathrm{v}$ pyramidal projection neurons. Neurosci. Res. 55, 105-115.

Molnar, Z., Metin, C., Stoykova, A., Tarabykin, V., Price, D. J., Francis, F., Meyer, G., Dehay, C., and Kennedy, H. (2006). Comparative aspects of cerebral cortical development. Eur. J. Neurosci. 23, 921-934.

Monsell, S. (1984). "Components of working memory underlying verbal skills: a 'distributed capacities' view," in International Symposium on Attention and Performance $X, \mathrm{Vol}$ 10 , eds H. Bouma and D. Bouwhuis (Hillsdale, NJ: Erlbaum), 327-350.

Morishima, M., and Kawaguchi, Y. (2006). Recurrent connection patterns of corticostriatal pyramidal cells in frontal cortex. J. Neurosci. 26 , 4394-4405.

Mountcastle, V. B. (2003). Introduction. Cereb. Cortex 13, 2-4.

Murphy, K. M., Beston, B. R., Boley, P. M., and Jones, D. G. (2005). Development of human visual cortex: a balance between excitatory and inhibitory plasticity mechanisms. Dev. Psychobiol. 46, 209-221.

Nakano, K., Tokushige, A., Kohno, M., Hasegawa, Y., Kayahara, T., and Sasaki, K. (1992). An autoradiographic study of cortical projections from motor thalamic nuclei in the macaque monkey. Neurosci. Res. 13, 119-137.

Nambu, A., Tokuno, H., Hamada, I., Kita, H., Imanishi, M., Akazawa, T., Ikeuchi, Y., and Hasegawa, N. (2000). Excitatory cortical inputs to pallidal neurons via the subthalamic nucleus in the monkey. J. Neurophysiol. 84, 289-300.

Nolte, J., and Angevine, J. B. (2000). The Human Brain in Pictures and Diagrams, 2nd Edn. Philadelphia: Mosby.

Northcutt, R. G., and Kaas, J. H. (1995). The emergence and evolution of mammalian neocortex. Trends $\mathrm{Neu}$ rosci. 18, 373-379.

O’Neill, J., Pleydell-Bouverie, B., Dupret, D., and Csicsvari, J. (2010). Play it again: reactivation of waking experience and memory. Trends Neurosci. 33, 220-229. 
Oorschot, D. E. (1996). Total number of neurons in the neostriatal, pallidal, subthalamic, and substantia nigral nuclei of the rat basal ganglia: a stereological study using the cavalieri and optical disector methods. J. Comp. Neurol. 366, 580-599.

Pare, D., Smith, Y., Parent, A., and Steriade, M. (1988). Projections of brainstem core cholinergic and non-cholinergic neurons of cat to intralaminar and reticular thalamic nuclei. Neuroscience 25, 69-86.

Parent, A., Smith, Y., Filion, M., and Dumas, J. (1989). Distinct afferents to internal and external pallidal segments in the squirrel monkey. Neurosci. Lett. 96, 140-144.

Parent, M., Levesque, M., and Parent, A. (2001). Two types of projection neurons in the internal pallidum of primates: single-axon tracing and three-dimensional reconstruction. J. Comp. Neurol. 439, 162-175.

Parent, M., and Parent, A. (2004). The pallidofugal motor fiber system in primates. Parkinsonism Relat. Disord. 10, 203-211.

Parent, M., and Parent, A. (2005). Single-axon tracing and threedimensional reconstruction of centre median-parafascicular thalamic neurons in primates. J. Comp. Neurol. 481, 127-144.

Parent, M., and Parent, A. (2006). Single-axon tracing study of corticostriatal projections arising from primary motor cortex in primates. J. Comp. Neurol. 496, 202-213.

Pearson, R. C., Brodal, P., Gatter, K. C., and Powell, T. P. (1982). The organization of the connections between the cortex and the claustrum in the monkey. Brain Res. 234, 435-441.

Penfield, W., and Rasmussen, T. (1968). The Cerebral Cortex of Man: A Clinical Study of Localization of Function. New York: Hafner Publishing Company.

Peters, A., Cifuentes, J. M., and Sethares, C. (1997). The organization of pyramidal cells in area 18 of the rhesus monkey. Cereb. Cortex 7, 405-421.

Price, D. J., Kennedy, H., Dehay, C., Zhou, L., Mercier, M., Jossin, Y., Goffinet, A. M., Tissir, F., Blakey, D., and Molnar, Z. (2006). The development of cortical connections. Eur. J. Neurosci. 23, 910-920.

Pucak, M. L., Levitt, J. B., Lund, J. S., and Lewis, D. A. (1996). Patterns of intrinsic and associational circuitry in monkey prefrontal cortex. J. Comp. Neurol. 376, 614-630.

Purves, D., Augustine, G. J., Fitzpatrick, D., Hall, W. C., Mantia, A.-S. L., McNamara, J. O., and Williams, S. M. (2004). Neuroscience, 3rd Edn. Sunderland: Sinauer Associates, Inc.
Rakic, P. (1995). A small step for the cell, a giant leap for mankind: a hypothesis of neocortical expansion during evolution. Trends Neurosci. 18, 383-388.

Ramnani, N. (2006). The primate cortico-cerebellar system: anatomy and function. Nat. Rev. Neurosci. 7, 511-522.

Rempel-Clower, N. L., and Barbas, H. (2000). The laminar pattern of connections between prefrontal and anterior temporal cortices in the rhesus monkey is related to cortical structure and function. Cereb. Cortex 10, 851-865.

Rockland, K. S. (1992). Configuration, in serial reconstruction, of individual axons projecting from area v2 to $\mathrm{v} 4$ in the macaque monkey. Cereb. Cortex 2, 353-374.

Rockland, K. S., Andresen, J., Cowie, R. J., and Robinson, D. L. (1999). Single axon analysis of pulvinocortical connections to several visual areas in the macaque. J. Comp. Neurol. 406, 221-250.

Rockland, K. S., and Drash, G. W. (1996). Collateralized divergent feedback connections that target multiple cortical areas. J. Comp. Neurol. 373, 529-548.

Rockland, K. S., and Ichinohe, N. (2004). Some thoughts on cortical minicolumns. Exp. Brain Res. 158, 265-277.

Romanski, L. M., Giguere, M., Bates, J. F., and Goldman-Rakic, P. S. (1997). Topographic organization of medial pulvinar connections with the prefrontal cortex in the rhesus monkey. J. Comp. Neurol. 379, 313-332.

Rouiller, E. M., and Durif, C. (2004). The dual pattern of corticothalamic projection of the primary auditory cortex in macaque monkey. $\mathrm{Neu}$ rosci. Lett. 358, 49-52.

Sadikot, A. F., Parent, A., and Francois, C. (1992a). Efferent connections of the centromedian and parafascicular thalamic nuclei in the squirrel monkey: a pha-l study of subcortical projections. J. Comp. Neurol.315, 137-159.

Sadikot, A. F., Parent, A., Smith, Y., and Bolam, J. P. (1992b). Efferent connections of the centromedian and parafascicular thalamic nuclei in the squirrel monkey: a light and electron microscopic study of the thalamostriatal projection in relation to striatal heterogeneity. J. Comp. Neurol. 320, 228-242.

Sakai, S. T., Inase, M., and Tanji, J. (1996). Comparison of cerebellothalamic and pallidothalamic projections in the monkey (Macaca fuscata): a double anterograde labeling study. J. Comp. Neurol.368, 215-228.
Sato, F., Lavallee, P., Levesque, M., and Parent, A. (2000). Single-axon tracing study of neurons of the external segment of the globus pallidus in primate. J. Comp. Neurol. 417, 17-31.

Satoh, K., and Fibiger, H. C. (1985). Distribution of central cholinergic neurons in the baboon (Papio papio). i. General morphology. J. Comp. Neurol. 236, 197-214.

Scheibel, M. E., and Scheibel, A. B. (1966). The organization of the nucleus reticularis thalami: a Golgi study. Brain Res. 1, 43-62.

Schmahmann, J. D., and Pandya, D. N. (1995). Prefrontal cortex projections to the basilar pons in rhesus monkey: implications for the cerebellar contribution to higher function. Neurosci. Lett. 199, 175-178.

Schmahmann, J. D., and Pandya, D. N. (2006). Fiber Pathways of the Brain. New York: Oxford University Press.

Schmahmann, J. D., Pandya, D. N., Wang, R., Dai, G., D’Arceuil, H. E., de Crespigny, A. J., and Wedeen, V. J. (2007). Association fibre pathways of the brain: parallel observations from diffusion spectrum imaging and autoradiography. Brain $130(\mathrm{Pt}$ 3), 630-653.

Schmahmann, J. D., Smith, E. E., Eichler, F. S., and Filley, C. M. (2008). Cerebral white matter: neuroanatomy, clinical neurology, and neurobehavioral correlates. Ann. N. Y. Acad. Sci. 1142, 266-309.

Sidibe, M., Bevan, M. D., Bolam, J. P., and Smith, Y. (1997). Efferent connections of the internal globus pallidus in the squirrel monkey: I. Topography and synaptic organization of the pallidothalamic projection. J. Comp. Neurol. 382, 323-347.

Sidibe, M., Pare, J. F., and Smith, Y. (2002). Nigral and pallidal inputs to functionally segregated thalamostriatal neurons in the centromedian/parafascicular intralaminar nuclear complex in monkey. J. Comp. Neurol. 447, 286-299.

Smith, Y., Bevan, M. D., Shink, E., and Bolam, J. P. (1998). Microcircuitry of the direct and indirect pathways of the basal ganglia. Neuroscience 86, 353-387.

Smith, Y., Raju, D. V., Pare, J. F., and Sidibe, M. (2004). The thalamostriatal system: a highly specific network of the basal ganglia circuitry. Trends Neurosci. 27, 520-527.

Solari, S. (2009). A Unified Anatomical Theory and Computational Model of Cognitive Information Processing in the Mammalian Brain and the Introduction of DNA Reco Codes. PhD thesis, University of California, San Diego.

Soloway, A. S., Pucak, M. L., Melchitzky, D. S., and Lewis, D. A. (2002). Dendritic morphology of callosal and ipsilateral projection neurons in monkey prefrontal cortex. Neuroscience $109,461-471$.

Squire, L. R. (2004). Memory systems of the brain: a brief history and current perspective. Neurobiol. Learn. Mem. 82, 171-177.

Squire, L. R., and Alvarez, P. (1995). Retrograde amnesia and memory consolidation: a neurobiological perspective. Curr. Opin. Neurobiol. 5, 169-177.

Squire, L. R., and Zola, S. M. (1996). Structure and function of declarative and nondeclarative memory systems. Proc. Natl. Acad. Sci. U.S.A. 93, 13515-13522.

Stanfield, B. B. (1992). The development of the corticospinal projection. Prog. Neurobiol. 38, 169-202.

Stephan, K. E., Hilgetag, C. C., Burns, G. A., O’Neill, M. A., Young, M. P., and Kotter, R. (2000). Computational analysis of functional connectivity between areas of primate cerebral cortex. Philos. Trans. R. Soc. Lond. B Biol. Sci. 355, 111-126.

Steriade, M. (2006). Grouping of brain rhythms in corticothalamic systems. Neuroscience 137, 1087-1106.

Steriade, M., Pare, D., Parent, A., and Smith, Y. (1988). Projections of cholinergic and non-cholinergic neurons of the brainstem core to relay and associational thalamic nuclei in the cat and macaque monkey. Neuroscience 25, 47-67.

Striedter, G. F. (2005). Principles of Brain Evolution. Sunderland: Sinauer Associates, Inc.

Surmeier, D. J., Ding, J., Day, M., Wang, Z., and Shen, W. (2007). D1 and d2 dopamine-receptor modulation of striatal glutamatergic signaling in striatal medium spiny neurons. Trends Neurosci. 30 228-235.

Szentagothai, J. (1975). The "moduleconcept" in cerebral cortex architecture. Brain Res. 95, 475-496.

Tanaka, K. (2003). Columns for complex visual object features in the inferotemporal cortex: clustering of cells with similar but slightly different stimulus selectivities. Cereb. Cortex 13, 90-99.

Tande, D., Feger, J., Hirsch, E. C., and Francois, C. (2006). Parafascicular nucleus projection to the extrastriatal basal ganglia in monkeys. $\mathrm{Neu}$ roreport $17,277-280$. 
Tanigawa, H., Fujita, I., Kato, M., and Ojima, H. (1998). Distribution, morphology, and gammaaminobutyric acid immunoreactivity of horizontally projecting neurons in the macaque inferior temporal cortex. J. Comp. Neurol. 401, 129-143.

Tanne-Gariepy, J., Boussaoud, D., and Rouiller, E. M. (2002). Projections of the claustrum to the primary motor, premotor, and prefrontal cortices in the macaque monkey. J. Comp. Neurol. 454, 140-157.

Tardif, E., Probst, A., and Clarke, S. (2007). Laminar specificity of intrinsic connections in Broca's area. Cereb. Cortex 17, 2949-2960.

Teyler, T. J., and Rudy, J. W. (2007). The hippocampal indexing theory and episodic memory: updating the index. Hippocampus 17, 1158-1169.

Thomson, A. M., and Bannister, A. P. (1998). Postsynaptic pyramidal target selection by descending layer iii pyramidal axons: dual intracellular recordings and biocytin filling in slices of rat neocortex. Neuroscience 84, 669-683.

Thomson, A. M., and Deuchars, J. (1997). Synaptic interactions in neocortical local circuits: dual intracellular recordings in vitro. Cereb. Cortex 7, 510-522.

Toro, R., Perron, M., Pike, B., Richer, L., Veillette, S., Pausova, Z., and Paus, T. (2008). Brain size and folding of the human cerebral cortex. Cereb. Cortex 18, 2352-2357.

Triarhou, L. C. (2007). A proposed number system for the 107 cortical areas of economo and koskinas, and brodmann area correlations. Stereotact. Funct. Neurosurg. 85, 204-215.
Trojanowski, J. Q., and Jacobson, S. (1976). Areal and laminar distribution of some pulvinar cortical efferents in rhesus monkey. J. Comp. Neurol. 169, 371-392.

Trojanowski, J. Q., and Jacobson, S. (1977). The morphology and laminar distribution of cortico-pulvinar neurons in the rhesus monkey. Exp. Brain Res. 28, 51-62.

Tsao, D. Y., Freiwald, W. A., Tootell, R. B., and Livingstone, M. S. (2006). A cortical region consisting entirely of face-selective cells. Science 311, 670-674.

Van Essen, D. C. (2005). Corticocortical and thalamocortical information flow in the primate visual system. Prog. Brain Res. 149, 173-183.

Velayos, J. L., Jimenez-Castellanos, J. Jr., and Reinoso-Suarez, F. (1989). Topographical organization of the projections from the reticular thalamic nucleus to the intralaminar and medial thalamic nuclei in the cat. $J$. Comp. Neurol. 279, 457-469.

Verzeano, M., Lindsley, D. B., and Magoun, H. W. (1953). Nature of recruiting response. J. Neurophysiol. 16, 183-195.

Vogt, B. A., Pandya, D. N., and Rosene, D. L. (1987). Cingulate cortex of the rhesus monkey: I. Cytoarchitecture and thalamic afferents. J. Comp. Neurol. 262, 256-270.

von Bonin, G., and Bailey, P. (1947). The Neocortex of Macaca mulatta. Urbana: The University of Illinois Press.

von Economo, C. (1929). The Cytoarchitectonics of the Human Cerebral Cortex. London: Oxford University Press.

Voogd, J. (2003). The human cerebellum. J. Chem. Neuroanat. 26, 243-252.
Voytko, M. L., Kitt, C. A., and Price, D. L. (1992). Cholinergic immunoreactive fibers in monkey anterior temporal cortex. Cereb. Cortex 2, 48-55.

Walker, A. (1940). A cytoarchitectural study of the prefrontal area of the macaque monkey. J. Comp. Neurol. 73, 59-86.

Walker, F. O. (2007). Huntington's disease. Lancet 369, 218-228.

Watakabe, A., Ichinohe, N., Ohsawa, S., Hashikawa, T., Komatsu, Y., Rockland, K. S., and Yamamori, T. (2007). Comparative analysis of layer-specific genes in mammalian neocortex. Cereb. Cortex 17, 1918-1933.

Witter, M., Groenewegen, H., Silva, F. L. D., and Lohman, A. (1989). Functional organization of the extrinsic and intrinsic circuitry of the parahippocampal region. Prog. Neurobiol. 33, 161-253.

Wolf, U., Rapoport, M. J., and Schweizer, T. A. (2009). Evaluating the affective component of the cerebellar cognitive affective syndrome. J. Neuropsychiatry Clin. Neurosci. 21, 245-253.

Yeterian, E. H., and Pandya, D. N. (1994). Laminar origin of striatal and thalamic projections of the prefrontal cortex in rhesus monkeys. Exp. Brain Res. 99, 383-398.

Yoshimura, Y., Dantzker, J. L., and Callaway, E. M. (2005). Excitatory cortical neurons form fine-scale functional networks. Nature 433 , 868-873.

Zaborszky, L., Wouterlood, F., and Lanciego, J. (2006). Neuroanatomical Tract-Tracing 3: Molecules, Neurons, and Systems. New York, NY: Springer. Zaitsev, A. V., Gonzalez-Burgos, G. Povysheva, N. V., Kroner, S., Lewis, D. A., and Krimer, L. S. (2005). Localization of calcium-binding proteins in physiologically and morphologically characterized interneurons of monkey dorsolateral prefrontal cortex. Cereb. Cortex 15, 1178-1186

Zaitsev, A. V., Povysheva, N. V., Gonzalez-Burgos, G., Rotaru, D., Fish, K. N., Krimer, L. S., and Lewis, D. A. (2009). Interneuron diversity in layers 2-3 of monkey prefrontal cortex. Cereb. Cortex 19, 1597-1615.

Zhou, F. W., Jin, Y., Matta, S. G., Xu, M. and Zhou, F. M. (2009). An ultrashort dopamine pathway regulates basal ganglia output. J. Neurosci. 29, 10424-10435.

Zikopoulos, B., and Barbas, H. (2006). Prefrontal projections to the thalamic reticular nucleus form a unique circuit for attentional mechanisms. J. Neurosci. 26, 7348-7361.

Conflict of Interest Statement: The authors declare that the research was conducted in the absence of any commercial or financial relationships that could be construed as a potential conflict of interest.

Received: 02 August 2011; accepted: 01 December 2011; published online: 20 December 2011.

Citation: Solari SVH and Stoner $R$ (2011) Cognitive consilience: primate non-primary neuroanatomical circuits underlying cognition. Front. Neuroanat. 5:65. doi: 10.3389/fnana.2011.00065 Copyright $(0) 2011$ Solari and Stoner. This is an open-access article distributed under the terms of the Creative Commons Attribution Non Commercial License, which permits non-commercial use, distribution, and reproduction in other forums, provided the original authors and source are credited. 